\title{
ENCUENTROS COLONIALES, HETERODOXIA Y ORTODOXIA EN EL VALLE CALCHAQUÍ NORTE BAJO EL DOMINIO INKA
}

\author{
Félix A. Acuto ${ }^{1}$
}

\section{* Introducción}

\section{Resumen}

Este artículo examina la vida social de las comunidades nativas del valle Calchaquí Norte, Argentina, durante la colonización inka. Esta situación de contacto cultural y colonialismo tuvo un profundo impacto en el mundo de la vida cotidiana de la sociedad nor-calchaquí. La dominación inka trajo aparejada una significativa transformación en la concepción vernácula de agencia, así como en la agencia misma de algunas personas. Así, algunos aprovecharon el nuevo contexto político para superar los constreñimientos estructurales del pasado y lograr un mejor posicionamiento en el espacio social. Sin embargo, y al mismo tiempo que ciertos individuos utilizaron las nuevas circunstancias con el fin de obtener beneficios personales, muchos otros se aferraron a los patrones indígenas, evitando la influencia de la cultura colonizadora sobre esferas y prácticas clave de la vida social nor-calchaquí.

Palabras claves: colonialismo - mundo de la vida - heterodoxia ortodoxia - período Inka.

\begin{abstract}
This article examines the social life of the native communities of the north Calchaquí Valley, Argentina, under Inka colonization. This situation of culture contact and colonialism had a profound impact on north Calchaquí society's lifeworld. Inka domination brought a significant transformation in indigenous ideas of agency, as well as in the specific agency of particular people. As such, certain persons took advantage of the new political context to overcome the structural constraints of the past and to achieve a better position within the new social space. Nonetheless, while some individuals used the new situation to obtain personal benefits, many others adhered to indigenous patterns, avoiding the influence of the colonizers' culture on key spheres and practices of north Calchaquí social life.
\end{abstract}

Key words: colonialism - lifeworld - heterodoxy - orthodoxy Inka Period.

Recibido: mayo 2010. Aceptado: diciembre 2011.
Los estudios antropológicos sobre los procesos coloniales han presentado, a grandes rasgos, tres vertientes. Por un lado, un gran número de trabajos se han interesado por investigar y discutir las distintas estrategias de dominación (económicas, políticas, ideológicas o culturales) de los colonizadores (Cooper y Stoler 1997; King 1979; Mitchell 1988; Rabinow 1989; Thomas 1994). Por otra parte, y ya en una segunda etapa, las transformaciones que el contacto cultural y el colonialismo produjeron sobre la sociedad colonizada, así como las acciones y estrategias de los dominados, pasaron a ser temas de interés de los estudios sobre el colonialismo. Estas perspectivas han criticado la visión de los colonizados como simples y pasivos recipientes y reproductores de la cultura y la ideología dominadora, cuestionándose el no reconocimiento de la agencia de los colonizados, quienes no solo se adaptan a los contextos de dominación, sino que también modifican, resisten, reconfiguran y resignifican las influencias de los colonizadores (Dielter 1998; Comaroff y Comaroff 1991, 1997; Dirks 1992; Thomas 1991, 1994. 1999). Dentro de esta tendencia se inscriben los denominados "estudios subalternos", los cuales han buscado desarrollar una historia desde abajo y, al mismo tiempo, decolonizar a las sociedades subalternas de los discursos, categorías, conocimientos y representaciones generadas por las sociedades dominadoras, los cuales han tendido a naturalizar la desigualdad y la colonización (Prakash 2000). Más recientemente, los estudios sobre el colonialismo han empezado a explorar las transformaciones que estos procesos de contacto cultural produjeron sobre

\footnotetext{
1 Instituto Multidisciplinario de Historia y Ciencias Humanas, CONICET. Saavedra 15, Piso 5, Buenos Aires (C1083ACA), ARGENTINA. Email: facuto@gmail.com
} 


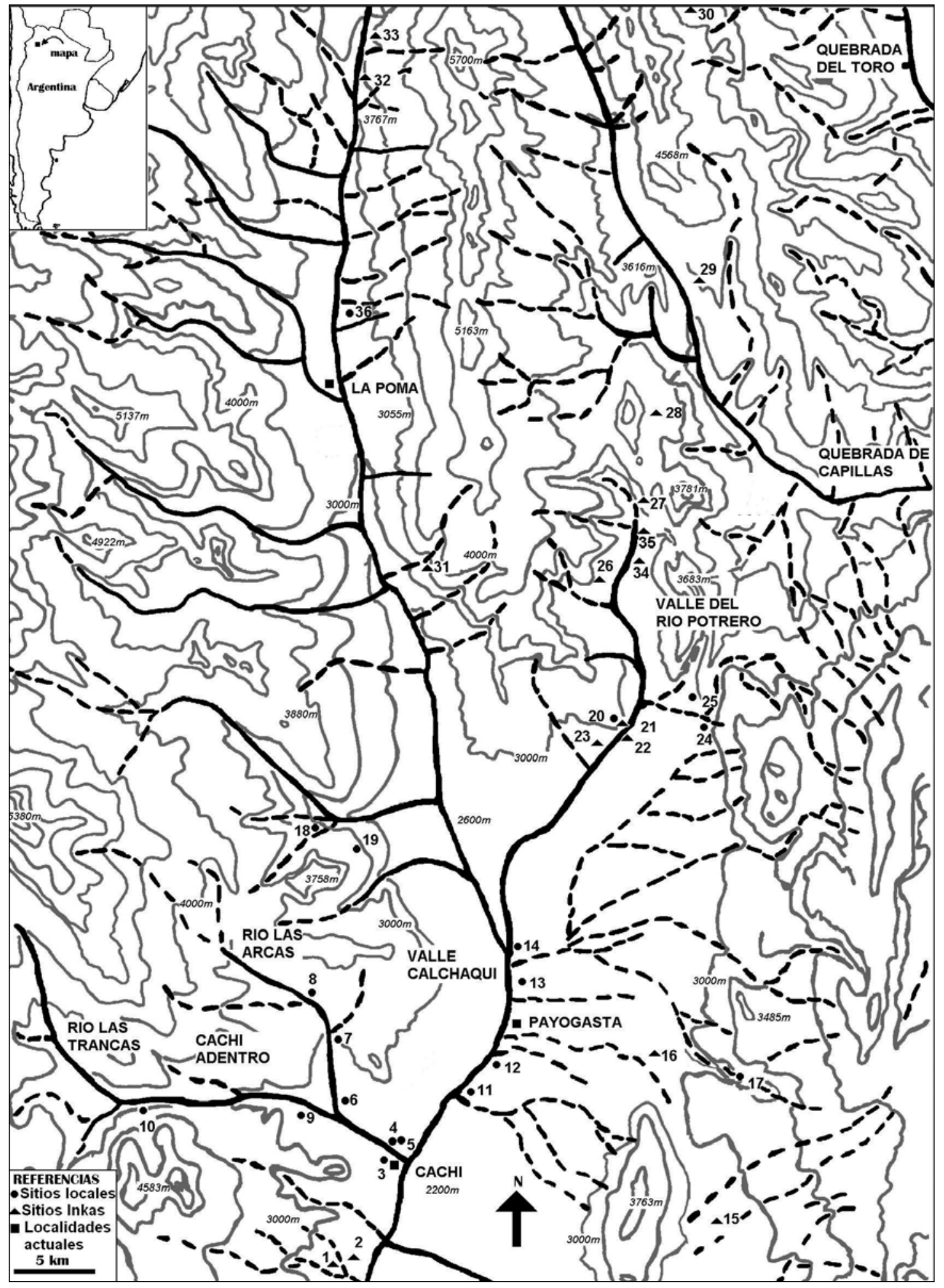

Figura 1. Valle Calchaquí Norte (Salta, Argentina). Sitios mencionados en este artículo: 1. La Paya, 2. Guitián, 5. Mariscal, 9. Loma del Oratorio, 17. Tonco 2, 20 a 22. Cortaderas, 23. Cortaderas Derecha, 26. Potrero de Payogasta, 35. RPoo2, 36. Esquina Azul y SLoo5. 
la misma sociedad colonizadora. En este último caso, el foco de análisis se ha puesto en cómo el encuentro con el otro influyó en la sociedad y cultura colonizadora (Chattopadhyay 2002; Davin 1997; Dirks 1992; Hall 2000; Said 1993; Stoler 1995).

En el caso de los estudios sobre el colonialismo inka, ha sido sin duda la primera tendencia la predominante. Los investigadores se han interesado en las estrategias militares y de defensa inkaicas, los proyectos económicos y la organización de la fuerza de trabajo colonizada, las estrategias de reorganización de las estructuras políticas indígenas, el reordenamiento de los patrones de asentamiento nativos, las migraciones forzosas de personas y comunidades denominadas mitimaes, el tipo de infraestructura y asentamientos instalados en las regiones ocupadas, y la naturaleza de las actividades ceremoniales y festivas que los inkas llevaban a cabo en los territorios ocupados, entre los temas más importantes. Sin embargo, también existen trabajos preocupados por entender el impacto que la dominación inka ejerció sobre las sociedades colonizadas (Acuto 2010; Alconini 2010; Jennings 2003; Gifford 2003; Leibowicz 2007; Mackey 2003; Troncoso 2004; Villacorta 2003). En varios de estos casos, se ha cuestionado el excesivo énfasis en la visión de arriba hacia abajo de la dominación inka, reclamándose la necesidad de estudiar los cambios producidos en la sociedad colonizada como consecuencia del proceso de colonización impuesto por el Imperio inka o Tawantinsuyu y las acciones y estrategias que los colonizados desarrollaron para lidiar con este imperio.

Este artículo explora el proceso de contacto cultural y colonialismo que se produjo en el valle Calchaquí Norte, Argentina (Figura 1), a partir de la llegada del Imperio inka. Específicamente, el trabajo está enmarcado en la segunda de las tendencias en el estudio del colonialismo. En otras palabras, se examinan las transformaciones que tuvieron lugar en la organización social y la cultura de las comunidades nor-calchaquíes bajo la dominación inka y las estrategias que los subordinados desarrollaron frente a la colonización. En primer lugar, explico cómo la colonización inka transformó la estructura social de las comunidades nor-calchaquíes, así como la idea establecida de agencia y, en algunos casos, la agencia misma de ciertos individuos. Sostengo que este nuevo contexto de colonización fue aprovechado por algunos sujetos locales para romper con los constreñimientos estructurales de la organización social nativa, expandiendo su capacidad de acción y logrando prestigio y poder a través de su asociación con los conquistadores foráneos. En segundo lugar, examino dos significativas esferas y prácticas culturales de los colonizados, analizando su cambio o persistencia bajo el control imperial. En este caso, argumento que mientras que un grupo de personas sacaba ventajas del nuevo contexto político para transformar su posición en la estructura social, la mayoría de los habitantes del valle Calchaquí Norte parecen haber preferido aferrarse a los patrones vernáculos.

\section{* Agencia, mundo de la vida y ENCUENTROS COLONIALES}

Este trabajo se enmarca en las teorías de la práctica y de la agencia. Éstas, especialmente las versiones de Bourdieu (1977, 1999, 2007) y Giddens (1979, 1995), han sido ampliamente discutidas y empleadas en la arqueología contemporánea. Sin embargo, no hay una sola lectura de estas teorías sociales, así como tampoco existe una única manera de aplicarlas a las interpretaciones del pasado (Pauketat 2001). La agencia, por ejemplo, tiene varios significados y ha sido usada en arqueología de diferentes modos y para explicar distintos fenómenos sociales (véase Dobres y Robb 2000; Dornan 2002). Por esta razón, antes de proceder con mi análisis, es pertinente explicar brevemente mi entendimiento de estos marcos teóricos y conceptos.

Las teorías de la práctica y la agencia emergieron en oposición a las perspectivas objetivistas (tal como el estructuralismo, el funcionalismo, las teorías del comportamiento, el evolucionismo, entre otros) y los acercamientos subjetivistas extremos (como por ejemplo la teoría de la elección racional, la hermenéutica y el existencialismo sartreano) en filosofía y ciencias sociales. Estas perspectivas sobre la vida social se enfocan en las prácticas cotidianas, rutinarias y "mínimas", ya que es en esta esfera en donde las sociedades se constituyen y reproducen. De acuerdo con las teorías de la práctica y de la agencia, existe una relación dialéctica entre la estructura social y las acciones y prácticas de las personas: la estructura da forma a la acción (habilitándola, encausándola y restringiéndola), pero al mismo tiempo las acciones y prácticas que las personas 
desarrollan, producen y reproducen las condiciones estructurales. A través de sus acciones, los sujetos no solo reproducen las estructuras sociales (especialmente las condiciones estructurales de las cuales ellos no son concientes), sino que también pueden transformarlas (especialmente a través de las consecuencias no intencionadas o no buscadas de sus acciones).

En las perspectivas de Bourdieu y Giddens, las personas no se encuentran rígidamente constreñidas por las estructuras sociales, respondiendo mecánicamente a reglas, leyes o normas que están más allá de su comprensión; pero tampoco son sujetos racionales y estratégicos capaces de superar o liberarse de las condiciones estructurales. Para estos autores las personas actúan en su vida diaria a través de un sentido práctico y están dotadas de una conciencia práctica. Así, los individuos no son ni autómatas que desarrollan acciones estructuralmente predeterminadas ni estrategas de tiempo completo llevando adelante acciones intencionales y bien planeadas para alcanzar sus objetivos. Por el contrario, la mayoría de las veces las personas actúan de manera práctica (en término de su habitus). Esto significa que la mayoría de las acciones que la gente desarrolla diariamente no constituyen actos conscientes e intencionales (orientados a alcanzar objetivos determinados y planificados), sino que son acciones prácticas.

Según estas teorías, los sujetos poseen la capacidad y conocimiento (o agencia) para modificar sus acciones de ser necesario, pero no de un modo estratégico sino de una manera práctica. Así, cualquier individuo "podría haber actuado de otra manera" (Giddens 1979: 56, traducción propia). Agencia implica, por tanto, actores entendidos quienes llegado el caso, y muy lejos de responder mecánicamente ante determinadas situaciones, tienen la capacidad de modificar sus acciones. En otras palabras, ante una situación dada, los agentes son capaces de llevar adelante una gama de acciones posibles y no un único curso de acción. Sin embargo, esto no quiere decir que el potencial que tienen los sujetos para la acción sea ilimitado; por el contrario, cuentan con un delimitado número de cursos de acción dependientes de los conocimientos y habilidades de la persona. Ningún agente tiene el conocimiento o pericias suficientes (o ilimitadas) como para actuar del modo que le plazca o para resolver todas las situaciones. En cada sociedad existen variaciones en la agencia de acuerdo con la posición en el espacio social, el poder y el capital cultural o económico que posean las personas. Asimismo, existen siempre constreñimientos estructurales sobre las acciones sociales; constreñimientos que varían históricamente, culturalmente y en relación con la posición del sujeto en la estructura social. En el curso cotidiano de su vida, hay algunos tipos de acciones que los agentes no desarrollan ya sea porque no les es permitido, no encuentran las condiciones propicias para hacerlo, no poseen el conocimiento o habilidad para hacerlo o porque no son conscientes que este curso de acción es posible.

En pocas palabras, la agencia es la capacidad de los sujetos para la acción práctica; el potencial y el conocimiento que una persona posee, como actor competente de su sociedad, para reflexionar ante situaciones dadas (a través de una conciencia práctica) y reorientar sus acciones, actuando de manera diferente. La agencia no involucra acciones estratégicas e intencionales, sino más bien la habilidad de los sujetos para cambiar el curso de sus acciones en correspondencia con situaciones específicas o circunstancias cambiantes, y en sintonía con sus propios objetivos. Es así que debemos diferenciar entre las acciones que se producen por el sentido práctico o habitus que las personas adquieren y aplican en su vida cotidiana y las acciones conscientes, intencionales y estratégicas que se planifican para alcanzar fines determinados.

Existen aspectos de la vida social que están más allá de la agencia o las acciones intencionales y estratégicas. Estos aspectos pertenecen a la esfera del mundo de la vida (Habermas 1987; Schutz y Luckmann 1977) o doxa (Bourdieu 1999, 2007). ${ }^{2}$ El mundo de la vida es el campo de la realidad inmediata donde participan diariamente las personas de formas que son tanto inevitables como pautadas, y que experimentan como algo dado por sentado y no cuestionado (Schutz y Luckmann 1977). En los contextos cotidianos, hay acciones, prácticas, disposiciones, objetos y arreglos espaciales que nadie cuestiona o trata de alterar por ser percibidos como naturales, normales, necesarios y neutrales. Las prácticas, acciones y aspectos materiales que pertenecen al campo del mundo de la vida, o que son dóxicos, es decir aquellos que son previ-

\footnotetext{
2 Aunque hay diferencias entre ambos conceptos, en líneas generales mundo de la vida (lebenswelt o lifeworld) y doxa describen el mismo fenómeno social.
} 
sibles, regulares y permanentes, sirven para simplificar y facilitar la comunicación y las relaciones sociales (Habermas 1987) y para reducir la carga cognitiva de los individuos. Ante determinados escenarios de interacción, el hallazgo de acciones esperables por parte de los que allí participan, y de un arreglo espacial y material anticipado, evita que las personas tengan que elaborar desde cero y reflexionar sobre cada acción que realizan. El encuentro con un contexto esperable y dado por sentado permite la acción práctica.

El mundo de la vida cotidiana es así el trasfondo familiar, no problemático e incuestionable de la vida diaria. Es la manera normal y esperada en que las actividades, espacios y objetos cotidianos están organizados y estructurados para contextos históricos y culturales específicos. El mundo de la vida es el ámbito más sedimentado y naturalizado de la vida social, lo que hace que se encuentre más allá de la conciencia de las personas. Por lo tanto, ni la agencia ni las acciones intencionales y estratégicas pueden modificarlo fácilmente, al menos mientras nada lo contradiga o muestre su arbitrariedad. Cuando se produce la cuasi perfecta correspondencia entre las estructuras objetivas y las estructuras internalizadas que resultan de la lógica de la simple reproducción, el orden cosmológico y político establecido es percibido como no arbitrario, es decir como un orden posible entre otros, sino como un orden autoevidente y natural que no se cuestiona. En estos casos, las aspiraciones de los agentes tienen los mismos límites que las condiciones objetivas de las cuales ellas son el producto (Bourdieu 1977: 164).

Según Bourdieu (1999), es en el contexto de crisis económico-política o en situaciones de contacto cultural cuando las personas se dan cuenta del carácter arbitrario de su mundo de la vida o doxa. Así también, ésta puede ser expuesta por sujetos informados y bien posicionados que actúan como "profesionales de la labor de explicitación" y que en ciertos contextos propicios pueden ser portavoces de los dominados (Bourdieu 1999: 247). En estas circunstancias, dos estrategias tienen lugar. Por una parte, algunas personas pueden aprovechar la oportunidad para intentar transformar las condiciones estructurales, desarrollando acciones orientadas a generar cambios en el orden social. La heterodoxia implica la contestación del orden establecido, mostrando su arbitrariedad, y simultáneamente la creación de formas alternativas de hacer y ser. Algunos individuos pueden servirse de este contexto de transformación para mejorar su posición. Por otra parte, aquellos que no desean el cambio social llevan a cabo estrategias que Bourdieu describe como ortodoxia, orientadas a preservar, a como dé lugar, el orden de las cosas. La ortodoxia, que es un sustituto imperfecto de la doxa, involucra una búsqueda consciente, y algo fundamentalista, de aferrarse o restablecer un ideal de orden previo, que no es necesariamente idéntico al orden vivido antes. La ortodoxia busca suprimir las alternativas.

Los procesos de contacto cultural, colonización y dominación engendran la transformación de la vida social y el mundo de la vida cotidiana de los colonizados. Por distintas razones, estos procesos impactan en las acciones de los sujetos y su agencia, ya sea porque: 1) Los colonizadores buscan intencionalmente cambiar las prácticas culturales de los colonizados; 2) los colonizados, o algún grupo dentro de la comunidad dominada, encuentra oportunidades sociales y materiales para modificar su situación; 3) nuevos cursos de acción que los dominados no podían realizar en condiciones estructurales previas, o directamente no estaban en su haber de conocimiento, se abren en las nuevas circunstancias; 4) cosas que eran dadas por sentado son ahora cuestionadas. Esta transformación (y quizá expansión) de la acción y de la agencia puede conducir al colonizado a intentar cambiar su posición dentro del nuevo orden, o puede llevarlo a pretender desesperadamente retener el orden previo a través de distintas estrategias, como la cooperación, la negociación o la resistencia.

\section{* La sociedad Nor-Calchaquí}

Para poder entender los cambios que se suscitaron en la vida social nor-calcahquí a partir de la llegada de los inkas, es necesario primero describir el contexto social en la región antes de la llegada del Tawantinsuyu. Desde hace algunos años, he comenzado a investigar la naturaleza de la sociedad que se desarrolló en el valle Calchaquí Norte entre el 1000 y el 1400/1470 AD, fecha en que se habría producido la conquista inka. Esta investigación disputa modelos anteriores que establecen que sociedades de tipo jefatura, caracterizadas por la desigualdad social y la estratificación económica y política institucionalizada, se habrían desarrollado en la región durante esta época, 
conocida como Período Tardío (DeMarrais 2001; Tarragó 2000). Como las fuentes históricas describen para momentos del contacto con los españoles (Lorandi y Boixadós 1987-88; Raffino 1983), es posible que para el período Tardío pudiera haber habido jefes en cada una de las comunidades más importantes de la región. Pero, al igual que los jefes que describieron los españoles, éstos habrían sido más bien líderes carismáticos hábiles en las negociaciones, diestros en el combate, con cierta influencia sobre la toma de decisiones y habilidad para coordinar a su comunidad, pero sin poder permanente y marcados privilegios sociales y materiales.

A través de prospecciones, detallados estudios de la arquitectura y organización espacial de varios sitios, análisis de la distribución del material de superficie en estos asentamientos, excavaciones, análisis de los materiales recuperados y estudio de colecciones de excavaciones previas, hemos desarrollado una idea distinta sobre la sociedad nativa pre-inkaica. Debido a que en otros lugares se han detallado estos análisis y justificado las interpretaciones (Acuto 2007, 2008; Acuto et al. 2008; Acuto et al. 2011; Acuto et al. 2012), en esta sección solo describiré resumidamente cómo entiendo a la sociedad nor-calchaquí del período Tardío.

El paisaje indígena durante esta época estaba compuesto, principalmente, por grandes poblados, asentamientos satélites más pequeños, algunos sitios defensivos o pucaras, amplias extensiones de campos agrícolas, puestos de pastoreo y concentraciones de grabados rupestres. La vida social durante el Período Tardío estaba fuertemente arraigada en los poblados principales. Era en estas localidades donde tenían lugar y se articulaban un número importante de prácticas y esferas sociales: vida doméstica y cotidiana, actividades de agregación comunitaria, prácticas funerarias, rituales, almacenaje, relación personas/ animales domésticos, socialización, reproducción biológica, crianza, producción simbólica y la manufactura y consumo de una gran cantidad de artefactos (vasijas cerámicas, artefactos de piedra, textiles, metalúrgica, instrumentos para la producción agrícola, entre los más importantes) (Acuto et al. 2008).

Estos asentamientos fueron conglomerados de estructuras que adquirían un patrón celular donde los edificios, de superficies semisubterraneas, compartían muros, ves- tíbulos y pasajes. Senderos artificialmente sobreelevados definían y dividían conjuntos discretos de estructuras residenciales. Cada asentamiento estaba conformado por varios de estos conjuntos o clusters de estructuras. Dentro de dichos clusters la circulación se efectuaba por arriba de los anchos muros, de más de un metro de ancho, y por rampas que descendían al interior de los recintos. Así, una amplia red de sendas permitía el movimiento entre y por arriba de los distintos edificios.

¿Cómo era la vida social en los poblados conglomerados donde transcurría la vida cotidiana y cuál era su sentido de lugar? Se puede decir que el orden material y espacial de estos asentamientos generaba tres tipos de experiencias, relaciones sociales y sentidos: 1) redundancia y homogeneidad material, 2) articulación y 3) apertura y permeabilidad.

1) Los grandes asentamientos conglomerados del valle Calchaquí Norte no contaban con estructuras monumentales, edificios administrativos o pertenecientes a instituciones políticas centralizadas. Tampoco hemos encontrado concentraciones de almacenes de acceso restringido, que muestren control sobre los recursos producidos, ni espacios públicos formalizados que indiquen una centralización y control del ritual. Por el contrario, cada cluster de estructuras dentro de un sitio posee uno o más espacios abiertos o plazas, sugiriendo que distintos grupos o familias dentro de la comunidad pudieron haber auspiciado eventos públicos. Además, están ausentes los monumentos funerarios, plataformas o estructuras que hayan involucrado una amplia movilización de mano de obra o representen un poder centralizado.

Estos sitios están básicamente conformados por edificios de carácter residencial y doméstico. No hemos observado diferencias significativas en la arquitectura de los complejos residenciales, ni tampoco entre los distintos clusters de estructuras, los cuales fueron edificados con materiales y técnicas constructivas similares. Se puede afirmar que al interior de los sitios la arquitectura es llamativamente homogénea. Sumado a esto, tanto el análisis del material de superficie como las amplias excavaciones efectuadas en algunos de estos sitios han demostrado una distribución amplia de los artefactos dentro de los asentamientos, sin vislumbrarse la existencia de un acceso diferencial a bienes especiales. Las actividades realizadas por los residen- 
tes de los distintos clusters fueron también llamativamente similares: procesamiento de alimentos, cocina, almacenaje, rituales funerarios y producción y uso de variados tipos de artefactos (líticos, cerámicos, textiles, metal e instrumentos de madera y hueso) (Acuto et al. 2008).

En conclusión, estos asentamientos conglomerados proponían a sus habitantes y visitantes un paisaje material homogéneo en donde todos residían en casas similares, empleaban y consumían objetos y recursos similares y realizaban actividades equivalentes. Más allá de compartir una identidad común, esta manera de habitar, donde cada unidad doméstica, y cada cluster de estructuras, era el reflejo material del otro, configuraba una vida social que evitaba la distinción y estratificación y reificaba la semejanza.

2) La organización espacial de estos asentamientos evitaba la segregación. Estos lugares constituían un continuum de arquitectura articulada que daba lugar a un todo unificado. Los poblados eran una red aglomerada de edificios sin sectores apartados y localizados en lugares especiales. Los senderos sobreelevados y los anchos muros/sendas construían una amplia red de circulación que permitía el acceso a prácticamente todos los rincones de un asentamiento, no habiendo notorias restricciones materiales al movimiento de las personas. Así, la forma en que los edificios estaban dispuestos y la circulación diseñada no generaba fragmentación sino que contribuía a la integración de sus residentes, facilitando su interacción cotidiana.

3) Al transitar por la amplia red de sendas internas sobreelevadas, y teniendo en cuenta que análisis arquitectónicos establecieron que aproximadamente entre $85 \mathrm{y}$ $90 \%$ del espacio construido en estos sitios conglomerados perteneció a grandes patios sin techo (Gifford 2003: 242), loci de la gran mayoría de las actividades que se realizaban en estos asentamientos (desde procesamiento de alimentos y cocina hasta producción de artefactos) (Díaz 1978-84, 1981), entonces podemos suponer que existió una gran accesibilidad visual que permitió a las personas, al circular, ver dentro de otras residencias, ponerse en contacto con otros vecinos, ser testigos de las actividades y rituales realizadas por otras unidades domésticas o reconocer los bienes que éstas consumían. Así, la privacidad no parece haber sido una preocupación central, ya que muchas actividades eran abiertas y expuestas a los ojos de la comunidad. Sumado a esto, el apiñamiento de la arquitectura hacía permeable los sonidos y olores, lo que también facilitaba conocer lo que sucedía en el poblado. Esta situación implicó un importante grado de control comunal, donde la acumulación de beneficios materiales debió haber sido altamente notable y fácil de regular y restringir. De este modo, la comunidad toda, a través de acciones simples y cotidianas, como desplazarse por el poblado, podía controlar y limitar las diferencias sociales.

En pocas palabras, el orden material y espacial de los poblados conglomerados nor-calchaquíes configuraba, cotidianamente, un mundo de la vida caracterizado por la comunalidad. En este mundo de la vida, la integración fue más importante que la fragmentación, la articulación y la permeabilidad más importante que la privacidad, la similitud más importante que la diferencia o la búsqueda de distinción o poder. Las condiciones estructurales que materializaba y reproducía el poblado sedimentaron una vida social caracterizada por la articulación y la homogeneidad material, donde la apertura y permeabilidad, que permitían un control comunal implícito, constituían condiciones clave para el mantenimiento del orden social.

\section{* Heterodoxia: El surgimiento de una NUEVA AGENCIA}

Como todo proceso de contacto cultural y colonialismo, la ocupación inka sobre el valle Calchaquí Norte dejó huellas sobre el mundo de la vida cotidiana de la sociedad local. Tal como hicieron en otras regiones del Tawantinsuyu, los inkas establecieron alianzas estratégicas o tuvieron una relación más fluida con algunas comunidades locales más que con otras y, dentro de estas comunidades, con algunas familias o grupos más que con otros. Como lo muestran varios estudios sobre la colonización inka a lo largo de los Andes, estas personas aprovecharon su relación con el Tawantinsuyu, copiando o manipulando estratégicamente la cultura material inkaica, para mejorar su posición y obtener poder (Alconini 2010; Grosboll 1993; Mackey 2003; Schreiber 1993; Villacorta 2003).

La evidencia arqueológica muestra que los inkas mantuvieron un vínculo especial, o una suerte de alianza, con la comunidad asentada en el sitio que hoy conocemos como La Paya (Figura 1). La influencia del Tawantinsuyu en La 


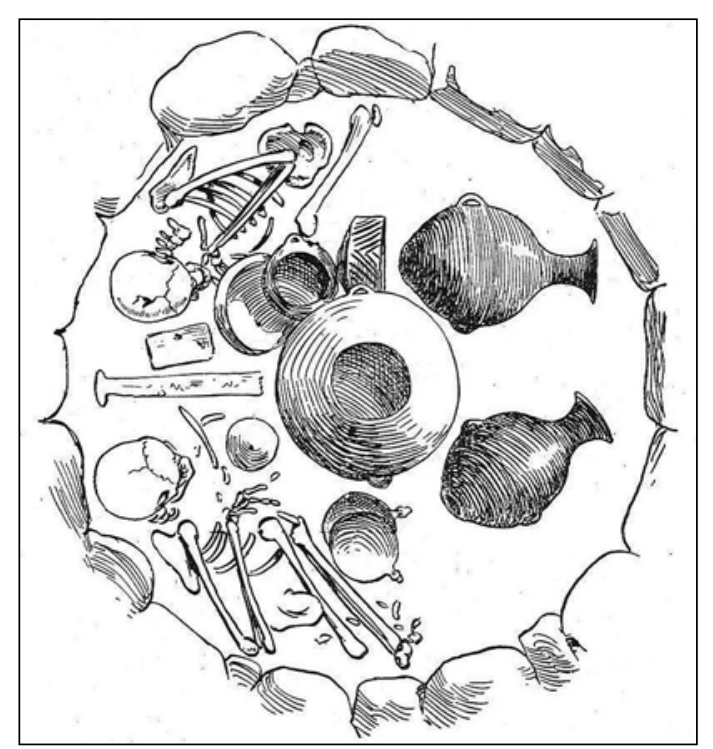

Figura 2. Tumba con objetos inkas de La Paya. Tumba 61 (tomada de Ambrosetti 1907-08).

Paya está atestiguada por 1) la presencia de objetos de estilo inkaico encontrados principalmente dentro de un grupo pequeño de tumbas, 2) la instalación de un particular edificio inka ubicado entre estructuras locales, y 3) la construcción de un típico sector público/ceremonial inkaico con residencias de elite asociadas frente a La Paya. Los tres son claros ejemplos de rupturas con el orden social y material vivido cotidianamente en La Paya antes de la intervención inka y de estrategias de agentes buscando transformar su posición dentro del espacio social.

A comienzos del siglo XX, Juan Bautista Ambrosetti encabezó una expedición de la Universidad de Buenos Aires que excavó 184 entierros en La Paya (Ambrosetti 1907-1908). ${ }^{3}$ Luego, en el año 1981, Pío Díaz, director del Museo Arqueológico de Cachi, excavó otros 11 sepulcros. De este universo de 195 entierros solo 23 presentaban ob-

\footnotetext{
3 En La Paya, Ambrosetti excavó 202 contextos que describe detalladamente. Aunque muchas publicaciones hacen referencia a las 202 tumbas de La Paya, varios de estos contextos no son tumbas sino vasijas enterradas sin restos mortuorios, estructuras circulares tipo cistas con objetos pero sin cadáveres, depósitos, ollas asociadas a fogón, entre otros. Además, algunos contextos de entierros de urnas recibieron un número único pero presentaban más de una urna con restos mortuorios.
}

jetos inkas en su ajuar junto con objetos de estilo y producción local (Figura 2). ${ }^{4}$ Si tenemos en cuenta que estos sepulcros contenían artefactos de origen local y cuentan con el mismo tipo de arquitectura y emplazamiento que las tumbas locales, podemos especular que aquellos que fueron enterrados en estas 23 tumbas eran nativos del valle Calchaquí Norte y no colonos mitimaes traídos por los inkas de otras regiones o representantes del Tawantinsuyu instalados en La Paya.

¿Qué significó esta transformación en el ritual fúnebre a partir de la inclusión de bienes inkas en algunas tumbas? En otro lugar hemos argumentado que la esfera mortuoria durante el período Tardío del valle Calchaquí Norte constituía otro contexto social donde la semejanza era reproducida (Acuto et al. 2011). En primer lugar, no existe ningún sepulcro que se destaque del resto por haber sido colocado en un lugar especial y exclusivo, o por haber tenido características edilicias particulares o monumentales. Las tumbas fueron construcciones circulares de piedra que no sobresalían del nivel del piso; todas de similares técnicas constructivas. En su mayoría estaban localizadas entre o dentro de los complejos residenciales, aunque también algunas fueron agrupadas inmediatamente adyacentes a los asentamientos. Segundo, no hay grandes diferencias entre las tumbas en cuanto al ajuar ya que la gran mayoría de los objetos colocados como ofrendas fueron artefactos usados previamente en los contextos domésticos y cotidianos. Tercero, entre las ofrendas son escasos los objetos relacionados con las tareas que se realizaban fuera del poblado (por ejemplo la caza o las actividades agrícolas y ganaderas) o aquellos involucrados con actividades rituales ocasionales (tal como las tabletas para aspirar alucinógenos o instrumentos musicales), y mucho más escasos los bienes foráneos. En pocas palabras, las cosas que se colocaron en los sepulcros hacían referencia a la vida diaria en los poblados y dentro de las casas. Es así que las tumbas miraban hacia adentro de la comunidad y a la vida de todos los días, haciendo referencia a lo vernáculo y pedestre por sobre lo exótico y lo foráneo.

\footnotetext{
4 Debido a que no se cuentan con fechados absolutos o relativos para las 172 tumbas sin objetos inkaicos, podemos especular que varias de éstas pueden ser del Período Tardío, mientras que otras tantas es posible que pertenezcan a la época inka, aunque mantuvieron el patrón local.
} 


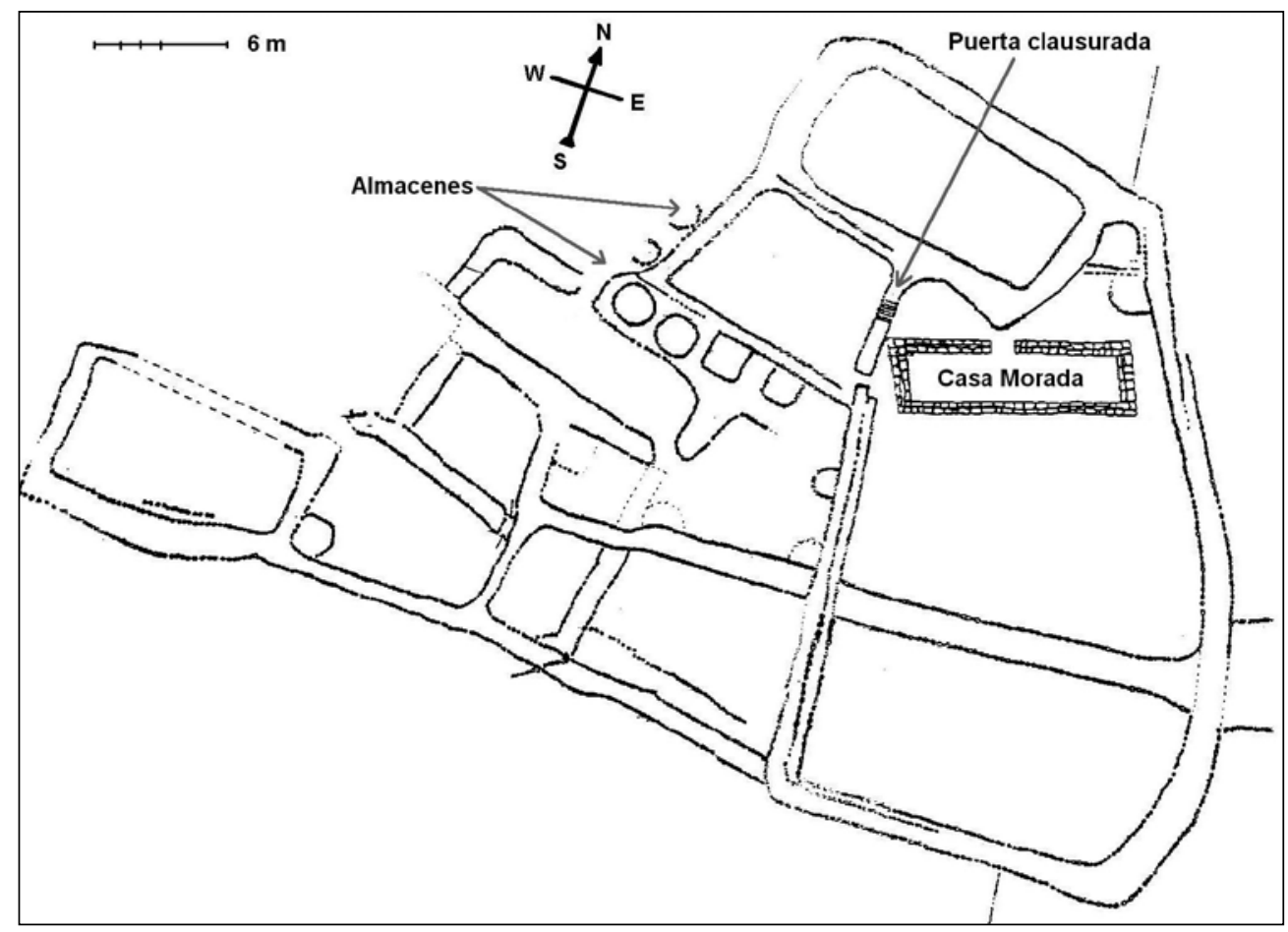

Figura 3. Plano sitio La Paya, sector Casa Morada (redibujado de González y Díaz 1992).

En el nuevo contexto social que produjo la colonización, aquellos que decidieron incluir objetos inkaicos en las tumbas de sus difuntos habrían roto con una tradición fúnebre sedimentada. Quienes produjeron estas tumbas comenzaron a asociarse con los conquistadores foráneos. No solo sus sepulcros dejaron de citar exclusivamente a la vida diaria y doméstica, comenzando a mirar hacia fuera del mundo de la vida cotidiana, sino que empezaron a generar distinción social a partir de la inclusión de objetos asociados con la colonización inka.

Pero el ritual mortuorio no fue la única esfera social y material afectada por el contacto con los inkas. Una de las construcciones más destacadas del sitio La Paya es un edificio de estilo inkaico denominado la Casa Mora$\mathrm{da}$ (Figura 3). Se trata de un recinto rectangular de 13,55 $\mathrm{m}$ por 4,24 $\mathrm{m}$ de lado, construido con una particular roca de arenisca rojiza obtenida a aproximadamente 10 $\mathrm{km}$ de distancia. La estructura presenta rasgos arquitectónicos típicamente inkaicos, marcadamente distintos de las técnicas constructivas nor-calchaquíes, tal como muros de rocas canteadas y con doble cara, forma rec- tangular y ángulos rectos, y hornacinas en una de sus paredes. La Casa Morada fue construida en la parte más elevada del sitio previo rearreglo de estructuras allí establecidas con anterioridad. Conectados con este especial edificio había una serie de recintos y patios de construcción local usados para una variedad de actividades, y cuatro (o quizá seis) almacenes emplazados en una plataforma elevada y otros dos enfrente de la Casa Morada, con una capacidad promedio de $3,3 \mathrm{~m}^{3}$ cada uno. Esta plataforma elevada con cuatro almacenes es una construcción más tardía, posiblemente contemporánea a la Casa Morada, la cual alteró los recintos adyacentes (González y Díaz 1992).

La Casa Morada presenta una única puerta orientada hacia el norte. Frente a esta puerta, a unos pocos metros, está el alto muro de una estructura adyacente que sirvió para bloquear el acceso visual al interior del edificio. Así, la única manera de mirar hacia adentro de la Casa Morada era parándose directamente frente a su única puerta. Para evitar que extraños tuvieran acceso directo a este peculiar edificio, se clausuró un acceso que conectaba el 
patio donde la Casa Morada fue construida desde un patio vecino y se relocalizó a unos pocos metros al sur en la misma pared (González y Díaz 1992). Este nuevo arreglo reorientaba la circulación hacia el interior de la Casa Morada. La nueva localización de la puerta prevenía un acceso directo a la Casa Morada, forzando un desvío que obligaba a las personas a caminar alrededor del edificio y usar un estrecho corredor para alcanzar la entrada (ver Figura 3). De este modo, tanto la vista como la circulación fueron controladas y la privacidad protegida.

Además de poseer este particular edificio, único en su clase, los residentes de la Casa Morada parecen haber obtenido una espectacular colección de bienes inkas. A comienzos del siglo XX una colección de cerámica inka, recipientes de madera, adornos personales en bronce, cobre, plata y oro fueron desenterrados del interior de esta estructura (Ambrosetti 1902; Boman 1908). ${ }^{5}$

¿Fue la Casa Morada una residencia, un templo o una estructura administrativa?, ¿quién empleo este particular edificio?, irepresentantes inkas o personas locales? Estas preguntas son difíciles de responder debido a que el registro arqueológico de la Casa Morada ha sido muy perturbado por saqueos. Sin embargo, existen algunas pistas que nos pueden ayudar a resolver este dilema.

A comienzos de la década de 1980, González y Díaz (1992) limpiaron el área de la Casa Morada y llevaron a cabo cuidadosas excavaciones dentro del gran patio en donde ésta está emplazada (ver Figura 3). Allí encontraron utensilios y restos de actividades domésticas, especialmente cocina y molienda. No hubo evidencias de otro tipo de actividades, lo que muestra que la Casa Morada era parte de un complejo residencial. Además, la presencia de artefactos de estilo local en la Casa Morada y dentro del patio que la contiene, así como el estilo arquitectónico de este último, sugiere que personas locales pudieron haber habitado este complejo residencial. ${ }^{6}$

\footnotetext{
5 Tanto Ambrosetti como Boman compraron colecciones de objetos de saqueadores que les aseguraron que provenían del interior de la Casa Morada, pero no queda claro si las encontraron dentro de un sepulcro o en cache de objetos. De todos modos, es importante señalar que dentro de la Casa Morada nunca fueron encontrados los restos de alguna tumba de piedra.

6 Otros investigadores que estudiaron el sitio concuerdan con esta idea (González 1982: 327; Hyslop 1990: 245).
}

Más allá de quien ocupó la Casa Morada, sí es seguro que esta estructura introdujo un quiebre en la homogeneidad material, la permeabilidad y articulación que se vivía en La Paya antes de la intervención inka. No solo este edificio se diferenciaba notablemente del resto por su forma, arquitectura, materiales de construcción y color, sino que también quienes allí residían habían accedido a un conjunto de artefactos que les permitió diferenciarse de los demás habitantes del poblado. Sumado a esto, la manera en que la Casa Morada fue emplazada, junto con el rearreglo intencional de las estructuras circundantes, muestran una búsqueda por mantener su interior oculto a los ojos de la comunidad. La inclusión de la Casa Morada en La Paya muestra que quienes allí residían optaron claramente por la distinción en lugar de la semejanza y la comunalidad.

Frente a La Paya, al otro lado del río y a tan solo $300 \mathrm{~m}$ de distancia, se ubica un sitio muy particular denominado Guitián (Figura 4). Su principal característica es la presencia de un espacio público/ceremonial inka de pequeña escala. Éste está compuesto por una plaza rectangular, una plataforma de piedra o ushnu de aproximadamente 1,5 m de alto casi en el centro de la plaza, un amplio edificio rectangular o kallanka y cuatro complejos residenciales inkas o kancha, todas típicas construcciones de los centros inkas provinciales. Los ushnus funcionaron, entre otras cosas, como estructuras desde donde el representante del Tawantinsuyu conducía rituales y realizaba libaciones y sacrificios. Las kallankas eran edificios tipo galpones, sin divisiones internas, usualmente establecidos al costado de las plazas y empleados en actividades administrativas o para hospedar oficiales de alto rango o tropas. En algunos sitios se ha sostenido que las kallankas funcionaron como templos.

Dentro del perímetro del sitio, hacia el este y noreste, se localizaron una serie de estructuras residenciales de tipo local, lo mismo que del otro lado del muro perimetral oeste, y luego de un barranco poco profundo.? Es importante destacar que las construcciones inkas presentan claras diferencias edilicias con las estructuras locales en cuanto a forma y técnicas constructivas.

Desde el año 2007 hemos comenzado a realizar estudios y excavaciones en Guitián. Dichas excavaciones nos han

7 Estas últimas estructuras aún no han sido mapeadas. 


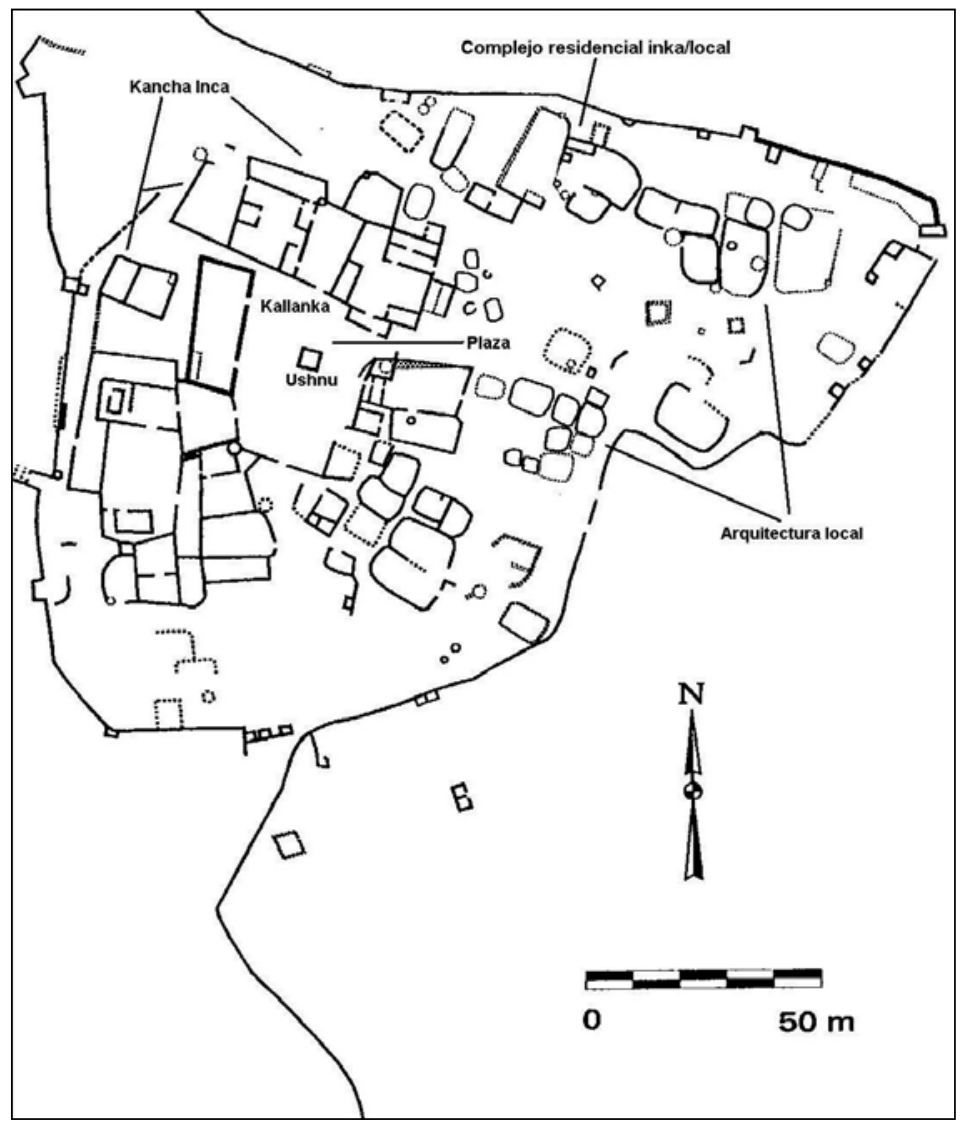

Figura 4. Plano sitio Guitián.

permitido comprobar que existió una ocupación local previa cuyos edificios fueron destruidos para colocar las construcciones inkas. Asimismo, hemos recuperado abundante evidencia (aún en análisis), tanto en la plaza como en algunos de los complejos residenciales, de consumo de alimento a gran escala y preparación de chicha, todos elementos típicos de las actividades ceremoniales y festivas inkas.

Una de las hipótesis de investigación del proyecto en Guitián sostiene que éste no fue una emulación local de la arquitectura inka sino que se trató de un centro ceremonial cuya construcción, así como las actividades allí realizadas, estuvieron promovidas por los inkas, probablemente con la intención de influir en las prácticas rituales y la cosmología de los habitantes de La Paya. Aunque fue un lugar auspiciado por los inkas, sostenemos que se trató de un centro ceremonial orientado al nivel local y empleado, habitado y controlado por un grupo de gente local. Al momento contamos con ciertos indicios que ayudan a apoyar esta idea. Primero, la obtención de una destacada cantidad de objetos inkas durante las recientes excavaciones en Guitián (jarras o aríbalos, platos, cerámica foránea y algunos objetos de cobre de estilo inka, tal como una maza estrellada), en tipos y proporciones similares a los encontrados en los principales centros administrativos inkas de la región (Acuto 2004; D'Altroy et al. 2000; Earle 1994), sugiere que fueron los inkas quienes canalizaban bienes a este asentamiento. Segundo, si se considera que el Tawantinsuyu había instalado en la región asentamientos con estructuras rituales de mejor calidad y mayor monumentalidad que las de Guitián, tal como en Potrero de Payogasta y Cortaderas (ver Figura 1), podemos entonces suponer que este espacio ceremonial de menor escala en Guitián estuvo orientado a la reproducción de los rituales inkaicos en la esfera de los colo- 
nizados indígenas. Por último, el hallazgo de artefactos de tipo local en una de las kancha excavadas en este sitio sugiere que familias locales no solo pudieron haber habitado los complejos residenciales de arquitectura local sino también aquellos de estilo inkaico.

La construcción de Guitián produjo una sectorización en el ambiente construido de La Paya. A partir de la intervención inka, este importante asentamiento nor-calchaquí dejó de ser un poblado construido como un todo continuo y materialmente homogéneo, para convertirse en un asentamiento dividido en dos partes enfrentadas y separadas por un río: La Paya y Guitián. Un sector local y otro inkaizado, uno con varios espacios de reunión comunal y el otro con un único espacio público central y formal, uno cotidiano y mundano y otro marcadamente ritual.

Dentro de Guitián, la segmentación era aún más evidente. Hubo una clara demarcación entre los residentes de las kancha inkas, quienes tenían un acceso directo al espacio público y a los edificio rituales/administrativos, y aquellos que habitaban en las casas locales, tanto dentro del perímetro del sitio como por fuera de éste, adyacentes al lado oeste del muro perimetral (ver Figura 4). Además, resulta evidente que quienes residían en las kancha buscaron preservar su privacidad. A diferencia de la arquitectura nativa, la inka no era semisubterránea ni de muros bajos y anchos que servían para la circulación por arriba de la superficie de las residencias. Por el contrario, las edificaciones inkas estaban compuestas por paredes altas, muchas de las cuales parecen haber superado los dos metros de altura. Esto tornaba imposible la observación al interior de los complejos residenciales inkas desde las vías de circulación o desde la plaza. Sumado a esto, puertas intencionalmente no alineadas y vestíbulos evitaban el acceso visual directo al interior de los sectores más íntimos de las kancha. En la Figura 4 se puede apreciar el campo visual restringido que alguien parado en la plaza tenía hacia el interior de las kancha.

Si como la evidencia sugiere quienes habitaban en la Casa Morada y en los complejos residenciales inkas y locales de Guitián eran nativos del valle Calchaquí Norte, los primeros convertidos en agentes del Tawantinsuyu y los segundos en personal de apoyo y servicio; entonces es posible afirmar que los inkas introdujeron a la vecina comunidad de La Paya a un mundo caracterizado por la fragmentación, la distinción y la privacidad. En este caso, un grupo de personas se separó del resto a partir de su asociación con los colonizadores. Este grupo construyó su distinción y estatus a través del uso de la cultura material inkaica y logró su poder a partir de la adquisición y control de un nuevo conocimiento ritual. Así, los inkas promovieron a algunos nativos de la región, no solo habilitándolos para controlar y reproducir prácticas ceremoniales inkaicas, sino también concediéndoles la agencia y el conocimiento para hacerlo.

La estructura social y la vida cotidiana en la comunidad de La Paya sufrieron una profunda disrupción durante la época inka. Al generar la construcción de edificios imperiales, promover la separación y la privacidad, y auspiciar el desarrollo de actividades rituales inkas, canalizando importantes cantidades de bienes del Tawantinsuyu a este lugar, los inkas produjeron la transformación de la dinámica social dentro de esta comunidad.

Con la dominación inka, un grupo de nativos comenzó a fracturar los principios de semejanza, homogeneidad material, permeabilidad y articulación que hasta ese momento caracterizaban al mundo de la vida nor-calchaquí. La nueva situación creó un contexto de heterodoxia en el cual nuevos objetos, nuevos edificios, nuevos conocimientos y nuevas actividades públicas empoderaron a un grupo de habitantes locales, proveyéndolos de nuevas capacidades, competencias y márgenes de acción. A través de su asociación con los colonizadores estas personas se vieron ante la posibilidad de superar las condiciones estructurales que la materialidad y espacialidad del poblado producían cotidianamente. Bajo la influencia inka, La Paya se convirtió en una comunidad fragmentada, donde unos pocos residentes se distanciaron del resto. Instituciones políticas centralizadas y actividades ligadas con los colonizadores extranjeros, distinción y polarización comenzaron a ser, así, experimentadas en este poblado.

La intervención inka en la región favoreció la emergencia de una nueva clase de agente y de un nuevo tipo de agencia. En este contexto histórico de contacto cultural y colonialismo, una elite local, diferenciada material y simbólicamente del común de la población, comenzó a constituirse. Esto debió haber traído aparejado la transformación en la percepción local de la agencia 
debido a que algunas personas comenzaron a obtener una capacidad de acción más amplia que los estándares vernáculos. ${ }^{8}$ Estas personas adquirieron la capacidad de desarrollar acciones (tal como prácticas de distinción, control sobre la distribución de bienes de prestigio inkaicos, acceso a conocimientos nuevos, acumulación de bienes, privacidad, control ritual y probablemente el control institucionalizado de la toma de decisiones) que no eran parte del mundo de la vida nor-calchaquí y que la estructura social local y la materialidad de los asentamientos locales habían restringido hasta entonces. Los inkas influyeron en la concepción indígena de agencia institucionalizando, legitimando y reificando la idea de un agente establecido por arriba de otros agentes en la estructura social. Así, la colonización inka produjo en la sociedad local no solo la transformación de la agencia nativa sino también la transformación de la idea misma de agencia.

Estos nuevos agentes aprovecharon la oportunidad ofrecida por la nueva situación política para superar los constreñimientos estructurales del mundo de la vida pre-inka, creando una heterodoxia. Ante los ojos de los demás miembros de la comunidad de La Paya (y otras personas en la región), aquellos que empleaban la cultura material, el conocimiento y las prácticas implantadas por el Tawantinsuyu se transformaron, en este contexto de dominación, en una nueva clase de agentes más informados y más competentes cuyo poder residía en su asociación con los conquistadores foráneos. Sin embargo, es posible que esta nueva posición no fuera totalmente deseada. Estos agentes promovidos por los inkas se convertían de alguna manera en colaboradores de la dominación, lo que dañaba las redes de solidaridad con su comunidad y podía provocar la alienación de sus propios vecinos. Quizá algunos de estos agentes promovidos por el Tawantinsuyu pudieron incluso resentir su nuevo estatus.

8 La presencia inka en sí misma también debió haber contribuido a cambiar la idea y percepción nativa de la agencia. Los inkas unificaron una región políticamente fragmentada, centralizando el poder, institucionalizando la desigualdad social y convirtiéndose en el estrato superior, por arriba de la influencia de cada uno de los jefes locales. Los representantes del Tawantinsuyu tuvieron la capacidad de controlar la economía y la política de toda la región, algo que ningún líder local había logrado.

\section{^ Ortodoxia: Esferas de Resistencia CULTURAL}

Como suele suceder en contextos de contacto cultural y colonialismo, así como existen entre los colonizados personas o grupos que aprovechan la nueva situación sociopolítica para transformar su posición, están aquellos que ortodóxicamente se aferran y buscan preservar los patrones locales previos. Tal como lo han demostrado una serie de investigaciones, éste ha sido el caso en varias regiones bajo el dominio inka donde los grupos locales evitaron su influencia en varias esferas de la vida social y material (Grosboll 1993; Muñoz y Chacama 1999; Rivera 2010; Rossen et al. 2010; Schreiber 1993). En esta sección del artículo, examino algunas acciones, esferas sociales y objetos que se constituyeron como campos de ortodoxia durante la colonización inka en la región.

\section{Arquitectura doméstica}

A partir de los datos obtenidos por extensos y sistemáticos trabajos de prospección y estudios arquitectónicos, se puede afirmar que un rasgo distintivo de la ocupación inka sobre el área norte del valle Calchaquí es el poco impacto que la arquitectura inka tuvo sobre la tradición arquitectónica local. ${ }^{9}$ Particularmente, son escasos los complejos residenciales locales que incorporaron edificios de estilo inka, que emularon rasgos de la arquitectura imperial o que mezclaron técnicas constructivas inkaicas y calchaquíes. Incluso algunos de los más importantes y extensos poblados indígenas de la región no muestran edificaciones que hayan emulado total o parcialmente la arquitectura inkaica. ${ }^{10}$ Existen, no obstante, algunos ejemplos, además del ya mencionado caso de La Paya, que vale la pena comentar. En algunos casos, la influencia de la arquitectura inka sobre la local es más evidente, mientras que en otros es mucho más dudosa.

9 El grueso de estas prospecciones fueron desarrolladas por Pío Pablo Díaz, fundador del Museo Arqueológico de Cachi, durante las décadas de 1970 y 1980, DeMarrais (1997) y Gifford (2003), durante la década de 1990, y mis propias investigaciones durante la primer década de 2000 .

${ }^{10}$ Por ejemplo: Las Pailas, Epifanio Burgos, La Hoyada, Borgatta, Mariscal, Tero, Quipón, Ruiz de los Llanos, Buena Vista y Valdez, entre otros. 


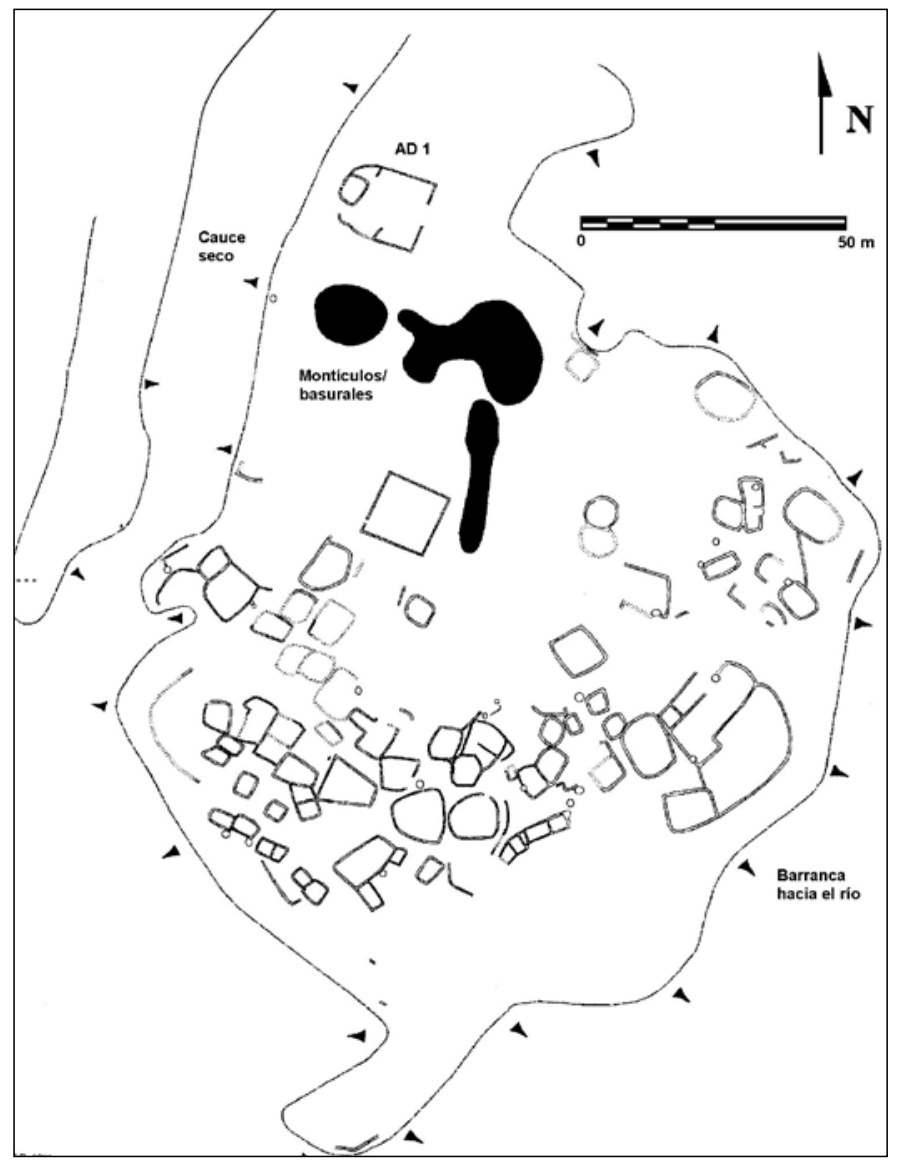

Figura 5. Sitio Cortaderas Derecha.

Cortaderas es un sitio complejo conformado por dos sectores inkas y dos sectores locales. Uno de estos últimos es Cortaderas Derecha, una pequeña aldea de arquitectura nativa (Figura 5). Durante los años 1996 y 1998 realicé tres temporadas de trabajo de campo en Cortaderas Derecha, las cuales consistieron en excavaciones, análisis arquitectónico y recolecciones de superficie. Estos estudios mostraron que éste fue el lugar de vivienda de familias locales reasentadas en directa asociación y vigilancia de los representantes del Tawantinsuyu, dedicadas principalmente a la producción y procesamiento de recursos vegetales y animales $y$, en menor medida, a la actividad metalúrgica orientada a la producción de lingotes de cobre (Acuto 2004).

Los complejos residenciales de Cortaderas Derecha fueron construidos con técnicas locales. Las casas eran más pequeñas que las residencias localizadas en los sectores inkas del sitio, y el trabajo invertido en su construcción significativamente menor que el empleado para levantar los edificios inkas de Cortaderas. No obstante, hay un complejo residencial en Cortaderas Derecha que exhibe algunos rasgos particulares que sugieren que sus habitantes pudieron haber emulado a los inkas (Figura 5, AD 1): 1) AD I se encontraba aislada del resto de los complejos residenciales y la única puerta del recinto, como en la Casa Morada, fue puesta en una posición que evitaba la posibilidad de ver a su interior directamente. 2) La manera en que $\mathrm{AD}$ I fue construido difiere de otras residencias de Cortaderas Derecha. En vez de tener los típicos muros anchos (de un metro de ancho en promedio), de doble hilera de piedras rellenas en el medio con sedimento y rocas pequeñas en el medio, sin mortero y con rocas verticales en su base que caracterizan a la arquitectura nor-calcha- 


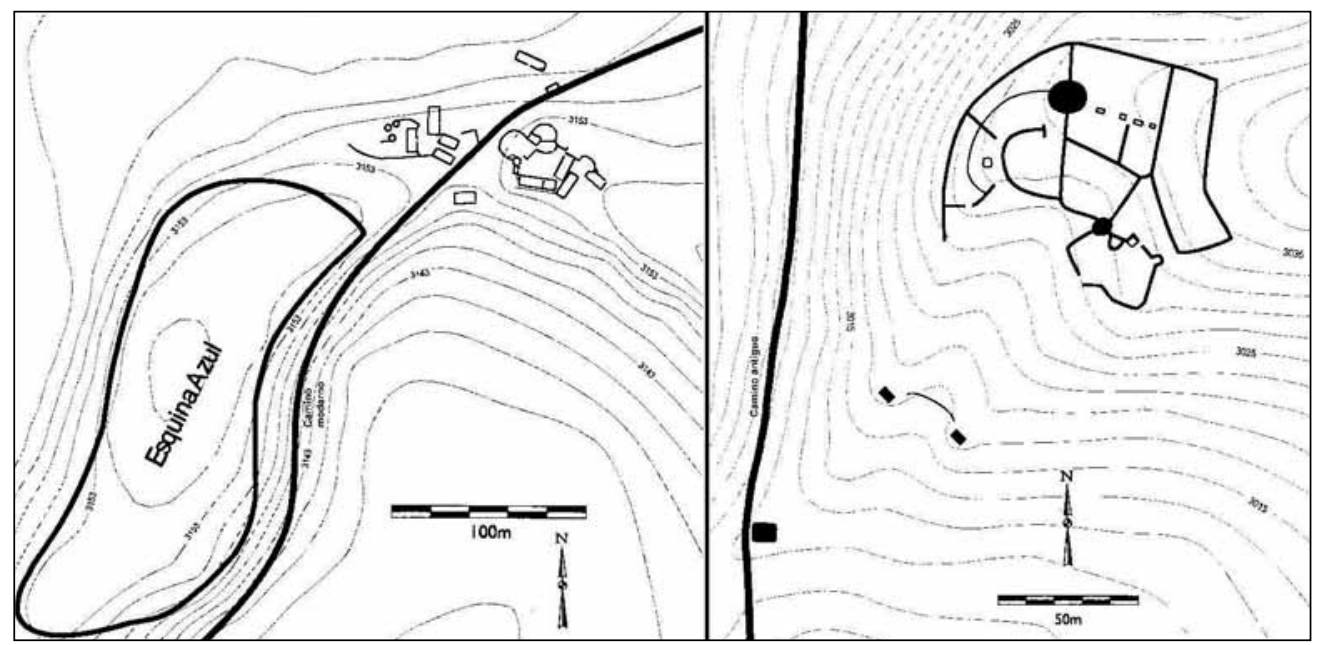

Figura 6. Sitios Esquina Azul/SLoo5 (derecha) y RPooz (izquierda), redibujados de Gifford (2003).

quí, las paredes de $\mathrm{AD}$ 1, como la arquitectura inka de la región, son de dos hileras de rocas contiguas tipo pirka y de 60 a $70 \mathrm{~cm}$ de ancho. Además, los muros fueron de doble cara, unidos con mortero y sin rocas verticales en su basamento. 3) A diferencia de los edificios locales, los ángulos de $\mathrm{AD}$ i no son redondeados sino rectos, típicos de la arquitectura inka. ${ }^{11}$ Aunque AD 1 representa un caso único en Cortaderas Derecha, lejos está de poder ser considerado un edificio inka ya que sus habitantes solo copiaron algunos pocos rasgos de la arquitectura inkaica.

Algo similar a Cortaderas Derecha sucede en Guitián. En la parte norte de este centro ceremonial inka se presenta un conjunto arquitectónico de tipo residencial que combina arquitectura inka y local. Si bien la mayor parte de este conjunto está formado por recintos de muro dobles, de ángulos redondeados y superficies semisubterráneas, en el interior de uno de los patios y en la parte sur hay adosadas estructuras rectangulares, de ángulos rectos y muros de pirka con mortero (Figura $4, \mathrm{~N}^{\circ} 6$ ).

De Lorenzi y Díaz (1976) detectaron en el sitio Loma del Oratorio, en el área de Cachi Adentro, estructuras (sin especificar cuántas) con técnicas constructivas diferentes a las del resto del poblado. Según estos investigadores, dichas construcciones de ángulos rectos y rocas canteadas

\footnotetext{
${ }^{11}$ Véase Gifford (2003) para un análisis y caracterización detallada de la arquitectura local e inka del valle Calchaquí Norte.
}

serían de tipo inkaico. Sumado a esto, en un ángulo de una de estas estructuras encontraron un entierro de niño dentro de urna con un ajuar compuesto por algunos objetos inkas. Nuestro proyecto realizó un estudio general de la arquitectura del sitio encontrándose dos estructuras rectangulares casi en el centro del asentamiento que podrían ser las mencionadas por estos investigadores. Las mismas aparecen articuladas con estructuras residenciales locales.

En el área de La Poma, en la sección norte del Valle, se encuentra el sitio SLoo5 (Gifford 2003). Se trata de un conjunto de edificios cuya disposición (tipo kancha residencial), su planta rectangular y las técnicas constructivas empleadas (muros de pirka de $70 \mathrm{~cm}$ de ancho, sin rocas verticales en la base) indicarían influencia inka. Este grupo de estructuras se encuentra emplazado a pocos metros de un amplio poblado local conglomerado con muro perimetral, denominado Esquina Azul (Figura 6, izquierda). Si bien no es posible aún determinar si se trataba de gente local inkaizada o representantes del Imperio habitando en asociación con un poblado local, sí se puede decir que, al igual que en La Paya y Guitián, la inserción de estos edificios proponía una división marcada entre local e inka.

Por último, en la quebrada de Tonco, Díaz (1992) describe un sitio pequeño, denominado Tonco 2 , con muros que combinan técnicas constructivas locales (paredes de hilera dobles anchas y rellenas) e inkas (rocas canteadas 
o acomodadas en sus caras planas). Además, se encontraron restos de cerámica inka en superficie.

Además de los cinco sitios hasta aquí mencionados, existen otros 10 sitios que presentan algunos rasgos arquitectónicos que sugieren una posible influencia inka. Estos casos son más dudosos ya que se trata de estructuras que presentan algunas técnicas constructivas de posible filiación inkaica, pero no transformaciones edilicias completas.

En la margen oeste del río Calchaquí se ubica una aldea pequeña, ocupada desde el período Temprano, que parece haber sufrido modificaciones durante la época inka. Este asentamiento, denominado RC-16, presenta un grupo de complejos residenciales de técnica constructiva local pero de patrón organizativo que recuerda a los amplios complejos residenciales del sitio inka Potrero de Payogasta, los cuales mezclan arquitectura inka y organización espacial local ${ }^{12}$ (DeMarrais 1997: 199). Cerca de RC-16, DeMarrais encontró una pequeña aldea local, RC-17, con al menos una estructura rectangular en el centro del sitio, la cual, según esta investigadora, parece de influencia inka (DeMarrais 1997: 313).

Durante las prospecciones en el área de La Poma, y cerca del pueblo del mismo nombre, se halla el sitio RC-65, de carácter defensivo y localizado en la cima de un cerro. Éste presenta algunos edificios cuyos muros forman ángulos rectos, lo que fue interpretado como indicador de la influencia inka (DeMarrais 1997: 351). Además, este sitio está asociado con el camino inka y cerámica inka fue recogida en superficie.

DeMarrais identificó también cierta influencia inka sobre la arquitectura de un grupo de sitios locales que presentan unos pocos edificios con muros de ángulos rectos, típicos de la arquitectura de tradición inkaica: RC-66 (aldea de tamaño medio en el área de La Poma), RC-117 (aldea pequeña sobre la margen oeste del río Calchaquí) y RP-25 (aldea pequeña en la Quebrada del río Potrero). También cree reconocer influencia arquitectónica inka en tres sitios

\footnotetext{
${ }^{12}$ En esta sección no está incluido Potrero de Payogasta por ser un caso inverso: un centro administrativo inka donde se ve la influencia local sobre lo inka. Además de las típicas estructuras público/ administrativas inkaicas, existe en el sitio un sector residencial en donde los edificios fueron construidos con técnicas inkas pero su organización espacial mezcló formas inkas y locales.
}

del área de La Poma que cuentan con algunas estructuras con muros de pirka en lugar de los típicos muros anchos y de doble hilera de tradición local. Estos son: RC-73 o Pum Pum (conglomerado defensivo), RC-77 (aldea de tamaño medio) y RC-81 (sitio residencial fortificado).

Otro caso mencionado por Gifford es RPooz, a $5 \mathrm{~km} \mathrm{al}$ norte del sitio inka Potrero de Payogasta. Se trata de un sitio de arquitectura y diseño espacial local que presenta cuatro plataformas de piedra al interior, cuya forma sugiere construcciones inkas (Figura 6, derecha). Si bien se puede decir que RPooz fue una unidad residencial local con corrales y montículos de basura, aún es difícil establecer la funcionalidad de las plataformas y su afiliación inkaica. ${ }^{13}$

Si tenemos en cuenta que a partir de las amplias prospecciones realizadas en la región se registraron un total de 203 sitios locales del período Tardío/Inka (desde grandes sitios defensivos en la cima de cerros a poblados de cientos de recintos localizados en el fondo de valle, y desde pequeñas aldeas o conjuntos residenciales entre campos de cultivos a puestos conformados por un único complejo residencial), y que de estos 203 sitios existen tan solo seis (3\%) casos con ejemplos de complejos residenciales locales que mezclaron arquitectura nativa e inkaica (La Paya, Cortaderas Derecha, Guitián, Loma del Oratorio, SLoo5 y Tonco 2), o 16 (8\%) si se incluyen aquellos más dudosos, podemos sostener entonces que los habitantes del valle Calchaquí Norte muy raramente construyeron sus casas incorporando técnicas constructivas inkas o edificios completos de estilo imperial articulados con los locales. Este porcentaje sería incluso mucho menor (muy probablemente menos del 1\%) si comparamos los miles de edificios presentes en estos 203 sitios con las pocas estructuras con arquitectura inkaizada halladas en estos 16 sitios.

¿Cuál es la razón de la poca presencia de copias de la arquitectura inkaica dentro de asentamientos locales? Esto puede significar dos cosas: o que la mayoría de los nativos del valle Calchaquí Norte no estuvieron interesados en reproducir las formas arquitectónicas inkas, ignorándolas o activamente rechazándolas; o que los inkas no permitieron a los colonizados producir copias totales de arquitectura

\footnotetext{
${ }^{13}$ Hay otros casos que nombra Gifford que son muy dudosos, por lo que no se incluyeron en el artículo. Esto son el sitio RLP16 y el sitio Peñas Blancas.
} 
imperial, sino que este fue un privilegio que los gobernantes del Tawantinsuyu solo daban a unidades domésticas aliadas. Considero que ambas posibilidades son factibles. En primer lugar, es muy posible que los inkas no hayan permitido a todo el mundo poseer un edificio de estilo inka dentro de sus poblados tan especial como la Casa Morada. La distribución restringida de objetos y arquitectura de estilo inka más allá de los sitios imperiales demuestra que los representantes del Tawantinsuyu usaron su cultura material como instrumento para crear alianzas y lubricar las relaciones políticas con sus súbditos. En otras palabras, los artefactos inkas no fueron para todos, sino que su distribución respondió a estrategias políticamente orientadas. Al mismo tiempo, el poder inka en la región no debió haber sido lo suficientemente coercitivo como para permitirles a los gobernantes imperiales inspeccionar cada uno de los edificios construidos en los asentamientos locales. Aunque los inkas pudieron haber restringido la construcción de un llamativo edificio puramente inka dentro de asentamientos locales (como la Casa Morada), los nor-calchaquíes pudieron, de haber querido, aplicar algunas de las técnicas constructivas inkaicas en sus construcciones. A pesar de esto, la tradición arquitectónica indígena parece haber sido muy escasamente influida por la presencia inka y tan solo un puñado de gente nativa eligió emular algunos rasgos de la arquitectura de los colonizadores. Así, los habitantes del valle Calchaquí Norte no construyeron sus casas, patios o corrales empleando técnicas arquitectónicas inkas, sino que mantuvieron sus típicas estructuras semisubterráneas, de muros dobles y anchos y ángulos redondeados.

\section{Estilo cerámico}

Dentro de la organización social nor-calchaquí hubo dos canales principales de expresión simbólica: la cerámica y el arte rupestre. El primer canal actuaba en el contexto de la vida cotidiana y doméstica y la esfera funeraria. Las vasijas eran lienzos cuya biografía transcurría en los poblados habitacionales y concluía, en algunos casos, en las tumbas. El segundo canal, por su parte, se concentraba en lugares especiales del paisaje, alejado de los sitios habitacionales, de sitios defensivos o de las áreas agrícolas (Acuto et al. 2012).

El repertorio de vasijas decoradas, definidas como estilo santamariano o calchaquí, ${ }^{14}$ no es muy amplio: pucos

${ }^{14}$ Este estilo cerámico lleva el nombre de la región donde se lo de-

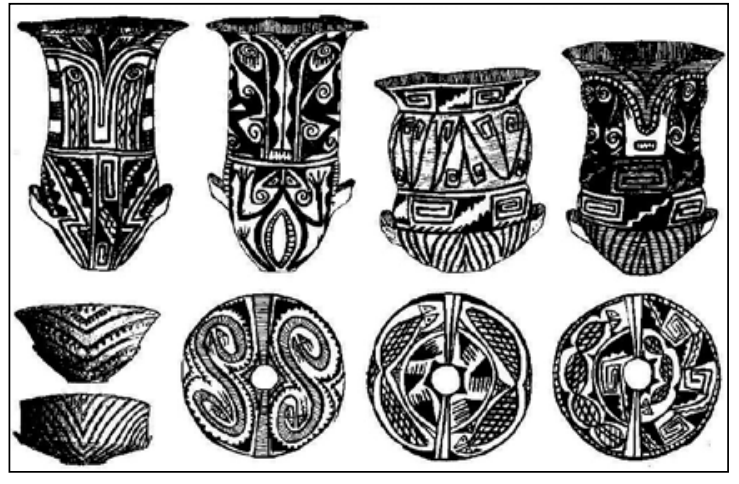

Figura 7. Alfarería santamariana o calchaquí: urnas y pucos (redibujados de Ambrosetti 1907-08).

(bowls), vasijas de cuellos alargados más conocidas como urnas (aunque no siempre cumplieron este rol), ollas medianas y grandes de cuellos evertidos y ollas medianas y pequeñas de bordes invertidos y labios convexos. Los pucos y las urnas no solo fueron las formas de mayor frecuencia del repertorio alfarero nor-calchaquí, ${ }^{15}$ sino que también, y por ser dos de los ítems materiales más comunes y populares en la región, pueden ser considerados uno de los sellos distintivos de la cultura material norcalchaquí (Figura 7).

La evidencia indica que la manufactura de la cerámica calchaquí no conformó una actividad especializada o centralizada, sino que fue producida a nivel doméstico por las distintas familias que habitaron los asentamientos. Además, y como se ha señalado más arriba, estas vasijas no fueron de uso y consumo restringido, sino que estuvieron ampliamente distribuidas entre todos los habitantes de los poblados (Acuto et al. 2008; Díaz 1978-1984, 1981).

Resulta interesante que la colonización inka tuvo un impacto imperceptible sobre la alfarería calchaquí. Son

finió por primera vez: el valle de Santa María en la provincia de Catamarca. Por sus claras connotaciones coloniales, en este trabajo se prefiere el término calchaquí para denominar a la cerámica decorada del valle Calchaquí Norte.

15 De la muestra de 247 vasijas calchaquíes analizadas para este estudio, el $83 \%$ corresponden a pucos (56\%) y urnas (27\%). El resto se reparte entre ollas grandes y medianas de cuellos y bordes evertidos (9\%), ollas de bordes invertidos y labios convexos (7\%) y vasijas misceláneas (1\%). 


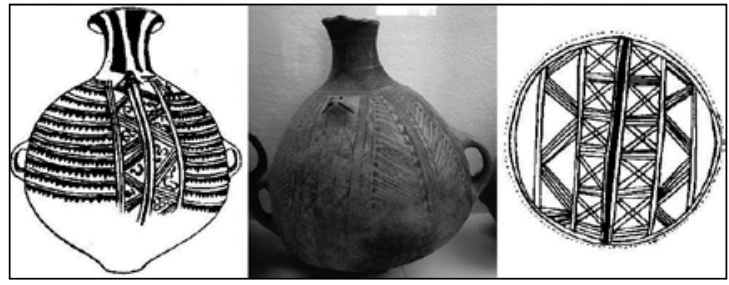

Figura 8. Vasijas inkas del valle Calchaquí Norte (redibujadas de Ambrosetti 1907-1908).

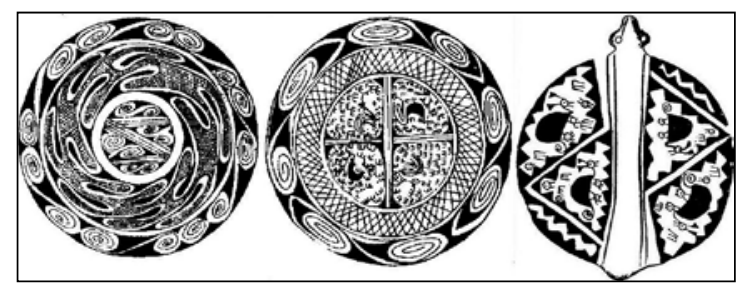

Figura 9. Vasijas inka-yavi/chicha (redibujadas de Ambrosetti 1907-1908).

extremadamente escasos, y algo dudosos, los casos de vasijas calchaquíes que presentan iconografía inka o relacionada con el mundo inkaico. Es decir, no hay casi combinaciones de símbolos inkas y locales sobre vasijas de producción y tradición nativa y no existe caso alguno de vasijas locales decoradas en su totalidad con composiciones inkas. Asimismo, tampoco parece haber ocurrido una transformación a partir de la influencia inka de la manera en que se organizaba la decoración de las piezas calchaquíes o en el modo en que se pintaban los dibujos.

Este no fue, sin embargo, el caso de las vasijas inkas, las que sí presentan elementos decorativos de tradición norcalchaquí en sus superficies. La incorporación de motivos no-inkas sobre piezas inkaicas fue un fenómeno común a lo largo del Tawantinsuyu (D’Altroy et al. 1994; Menzel 1959; Hyslop 1993). Hay opiniones divergentes sobre el origen de este tipo de vasijas, a las que se ha denominado Inka Mixtas. Si bien algunos investigadores consideran que éstas representan casos de emulación local del estilo imperial, para otros fueron fabricadas dentro de la esfera inka, por lo que su producción y distribución habría estado en manos del Tawantinsuyu. En este caso, se ha argumentado que la inclusión de motivos locales en vasijas inkas habría sido un mecanismo de dominación simbólica a través del cual los inkas representarían su dominio y posesión de dicha sociedad y su fuerza de trabajo (Hayashida 2003: 312).

En el caso del valle Calchaquí Norte, además de encontrarse vasijas de forma y decoración inka (Figura 8), existe un grupo importante de cerámica Inka Mixta representada por piezas inkas, tales como aríbalos, platos y jarras pequeñas de asa lateral, que presentan decoración: a) yavi/ chicha, grupo étnico del sur de Bolivia y extremo norte de Argentina (Krapovickas 1983); este estilo cerámico es también conocido como Inka Paya o Casa Morada Polícromo (Figura 9); b) de la Quebrada de Humahuaca (región ubicada a aproximadamente $150 \mathrm{~km}$ en línea recta al noreste del valle Calchaquí) (Figura 10, izquierda y centro); c) pacajes (grupo étnico del área circuntiticaca meridional) (Figura 10, derecha); y d) santamariana o calchaquí (Figura 11). Estas últimas incluyen tanto vasijas de formas inkas con dibujos de la alfarería calchaquí como piezas inkas con superficies negras pulidas, la cual también fue un tipo de decoración cerámica de origen local. ${ }^{16}$ Además, y tal como muestra la Figura 12, también se presentan piezas que combinan los cuatro tipos decorativos mencionados junto con decoración inka.

La evidencia indica que las vasijas Inka Mixtas encontradas en el valle Calchaquí Norte no fueron manufacturadas en el ámbito local sino que pertenecen a la esfera de producción inka y, por lo tanto, su distribución fue controlada por los representantes del Tawantinsuyu. Primero, la materia prima, las pastas y las técnicas de aplicación de los dibujos en las vasijas calchaquíes y las Inkas Mixtas son marcadamente diferentes, lo que indica que pertenecen a tradiciones tecnológicas distintas. Segundo, la cerámica Inka Mixta, como la inka, solo fue encontrada en sitios inkas y en un puñado de sitios locales, lo que sugiere que fue un producto de circulación restringida. Tercero, la cerámica inka y la Inka Mixta presentan una alta correlación, lo que sugiere que pertenecían a canales paralelos de distribución (Williams 2004: 231). Cuarto, análisis macroscópicos y de composición química de las pastas de las cerámicas Inka Mixtas del valle Calchaquí Norte

\footnotetext{
${ }^{16}$ Las vasijas negras pulidas tuvieron una larga tradición en el valle Calchaquí Norte, estando presentes en la región desde el Período Temprano o Formativo (500 AC a 500 DC) hasta el Período Tardío.
} 


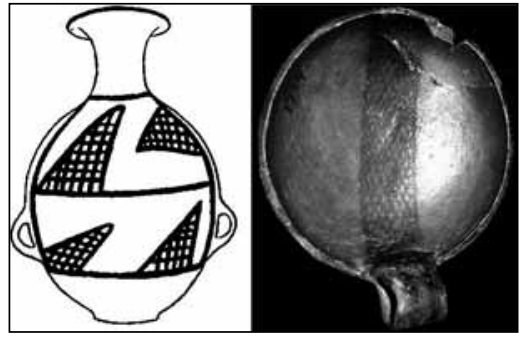

Figura 10. Vasijas inka-humahuaca (redibujada de Ambrosetti 1907-1908).

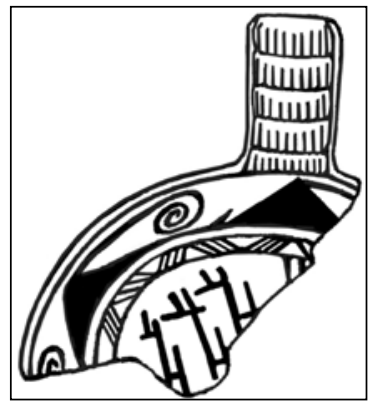

Figura 11. Vasijas inka-pacajes

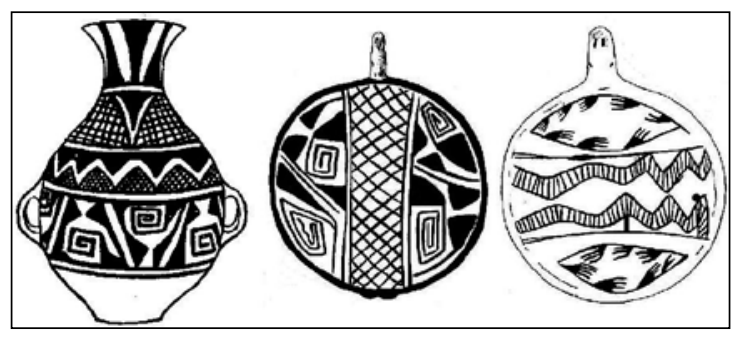

Figura 12. Vasijas inka-calchaquí (redibujadas de Ambrosetti 1907-1908).

indicaron que esta alfarería no fue manufacturada en la región sino importada del Altiplano (Williams 2004: 232233). En quinto lugar, vale citar un argumento interesante de Dillehay (2003), quien sostiene que las vasijas Inka Mixtas no podrían haber sido producto de una imitación eventual local debido a que la confección de formas como los aríbalos o los keros necesitan de un conocimiento sofisticado y nuevas habilidades motoras. Todo esto señalaría que fueron los inkas quienes decidieron confeccionar estas vasijas de típicas formas inkaicas que incorporaban símbolos de los colonizados en sus superficies.

Sin embargo, tal como se señaló, lo contrario casi no se dio. Fue prácticamente nula la incorporación de formas de organizar la decoración y de motivos inkas o asociados con los inkas en las típicas vasijas calchaquíes, tal como los pucos y las urnas. En este punto es importante aclarar que con motivos asociados me refiero a aquellos motivos no-inkas que llegaron a la región inscriptos en vasijas inkas y que, por lo tanto, ante los ojos de la gente local eran motivos de los colonizadores. En este caso los motivos yavi/chicha y pacajes, aunque no los provenientes de la Quebrada de Humahuaca, región con la cual existieron contactos desde antes de la llegada de los inkas (Gifford 2003: 175-180 y 199).

A partir del estudio de una colección de 247 vasijas calchaquíes depositadas en el Museo Etnográfico J. B. Ambrosetti de Buenos Aires, Argentina (ME), en el Museo Arqueológico P. P. Díaz de Cachi (MAC) y publicadas en los textos de Ambrosetti (1907-1908) y Debenedetti (1908), fue posible confirmar la escasa influencia inka sobre la cerámica calchaquí. ${ }^{17} \mathrm{El}$ primer paso fue comparar la alfarería calchaquí y la inka. Existen marcadas diferencias entre ambas tradiciones cerámicas en cuanto a: 1) pastas (las calchaquíes tienen pastas más porosas y con más mica mientras que las inkas presentan pastas mucho más compactas), 2) tratamiento de superficie (las piezas calchaquíes con decoración dibujada tienen superficies alisadas y las inkas pulidas), 3) tonalidades (dibujos negros, mayoritariamente, o rojos sobre fondo crema o rojo opaco caracterizan a la cerámica calchaquí, mientras que dibujos negros sobre fondos cremas, rojos o naranjas brillantes son típicos de la alfarería inka), 4) técnicas de dibujo (las vasijas calchaquíes presentan dibujos de líneas gruesas y las inkas suelen tener motivos dibujados

${ }^{17}$ La mayoría de estas piezas cerámicas provienen de contextos funerarios de la La Paya y Tero, dos sitios locales con gran influencia Inka. En un primer momento solo se iban a incluir en este análisis piezas cerámicas calchaquíes provenientes de contextos con fechados del período Inka o asociados con objetos inkaicos. No obstante, al ser éstas poco numerosas decidí incluir también las vasijas recuperadas de contextos sin objetos inkas. Al no contar con fechados o seriaciones confiables para estos contextos, asumí que si bien algunas piezas deben ser del Período Tardío, otros son seguramente de época inka. 
con líneas finas y marcadas), 5) estructura del diseño o la forma en que la decoración se organiza en la superficie de las vasijas, y 6) iconografía. Si bien todos estos aspectos fueron significativos ya que están asociados con tradiciones tecnológicas, formas de hacer, memorias y sentidos, mi estudio se centró en el análisis de las estructuras del diseño y la iconografía por estar ambos más directa y obviamente relacionados con dos imaginarios distintos y dos maneras diferentes de representar aspectos de la cosmología andina. Secundariamente, y debido a las tan marcadas diferencias entre uno y otro estilo cerámico, examiné también las técnicas de dibujo.

A partir de esta aproximación general, el segundo paso de este estudio fue: establecer los rasgos generales de la estructura del diseño inka, identificar la iconografía que el Tawantinsuyu trajo al valle Calchaquí Norte, tanto la inka propiamente dicha como la de sociedades colonizadas de otras regiones que aparecen en las piezas inkas, identificar la estructura del diseño del estilo santamariano o calchaquí, y determinar los motivos locales pre-inkaicos.

En cuanto a la estructura del diseño, si bien hay aspectos compartidos en la manera en que se organizaba la decoración en las vasijas inkas y las locales (aunque en diferentes proporciones, ambas presentan patrones de decoración verticales y horizontales y divisiones duales), hay cuatro rasgos novedosos que la alfarería del Tawantinsuyu introdujo en la región: 1) En cuanto a las formas abiertas, mientras que la decoración principal en los pucos calchaquíes está siempre en la parte externa (Figura 7), en los platos inkas se concentra en el lado interno de las piezas (Figuras 8 a 12). 2) También en las formas abiertas inkas, en varias ocasiones la decoración se presenta organizada a partir de un patrón cuatripartito ( $\mathrm{Fi}$ guras 9 centro y 12 derecha), mientras que en las locales el patrón es siempre dual. Es importante destacar que la cuatripartición fue uno de los principios de organización social y espacial más importantes del Tawantinsuyu, por lo que esta representación gráfica puede estar haciendo referencia a este aspecto de la ideología inka. 3) Las formas cerradas inkas, especialmente los aríbalos, suelen presentar decoración en un solo lado, mientras que las formas cerradas locales (tal como las urnas y las ollas de bordes evertidos e invertidos) se decoraron en ambas caras. 4) Tanto en los platos como en las formas cerradas inkas (aríbalos y jarritas de asa lateral) la decoración es-

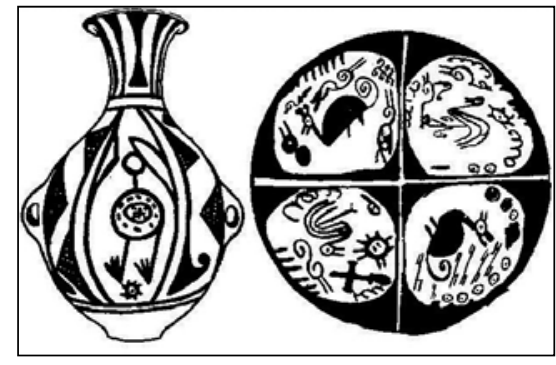

Figura 13. Vasijas inkas que combinan varios estilos (redibujadas de Ambrosetti 1907-1908). A la izquierda aríbalo que combina motivos de la quebrada de Humahuaca (líneas con triángulos reticulados) y de la región Calchaquí (figura zoomorfa central). Esta última es una versión algo modificada de un motivo local. A la derecha plato que presenta motivos InkaPaya (figuras zoomorfas), Pacajes (llamitas estilizadas) e inkas (círculos con punto central, cruz y S).

tuvo en algunos casos colocada dentro de triángulos u óvalos que delimitaban espacios donde se incluían varios dibujos pequeños dispuestos de manera algo desordenada (Figuras 9 y 12 derecha).

Con el objeto de reconocer la posible influencia iconográfica inka sobre las vasijas locales, se clasificaron los motivos más típicos de la cerámica calchaquí y los motivos que se encuentran en la alfarería inka. En este último caso, se separaron los motivos inkas clásicos que aparecen en las vasijas encontradas en el valle Calchaquí Norte de los motivos asociados a lo inka, es decir dibujos no locales que llegaron al valle Cachaquí Norte con las vasijas inkas. Asimismo, se tuvieron en cuenta algunos motivos típicos inkas que no se encuentran en las cerámicas inkas encontradas en nuestra región, pero que aparecen frecuentemente a lo largo de los Andes, tanto en cerámica del Tawantinsuyu como en otros soportes. Como se puede ver en la Figura 13, hay grandes diferencias entre los motivos calchaquíes y los inkas.

También se prestó atención a variaciones en las técnicas de dibujo. Considerando las drásticas diferencias entre las formas de trazado, se examinaron las vasijas calchaquíes en búsqueda de motivos que emulasen la técnica inka de dibujo.

Una vez establecidos los criterios de análisis, se procedió a inspeccionar las vasijas calchaquíes, obteniéndose los 
siguientes resultados. Primero, en solo un caso se encontró una de las mencionadas cuatro formas inkaicas de organizar la decoración aplicadas en vasijas calchaquíes. Segundo, en solo nueve de las 247 vasijas estudiadas se detectaron posibles, aunque algo dudosas, influencias iconográficas inkas. Tercero, no se encontraron piezas calchaquíes pintadas con las técnicas de dibujo de la alfarería inka. A continuación se describe cada caso:

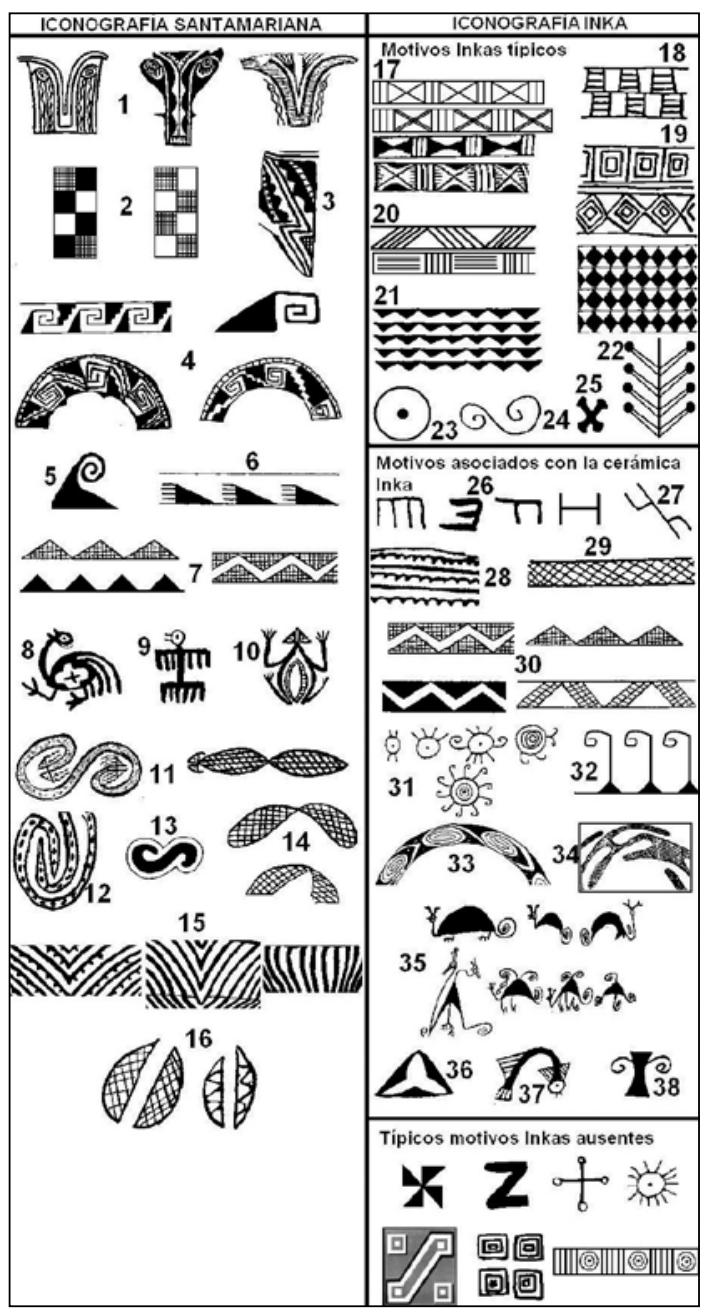

Figura 14. Tabla con motivos santamarianos o calchaquíes (izquierda) e inkas (derecha). Estos últimos están divididos en motivos típicamente inkaicos que aparecen en la cerámica inka del valle Calchaquí Norte, motivos asociados con la cerámica inka (es decir, aquellos no inkas y no locales que aparecen en la cerámica inka encontrada en la región), y dibujos inkas típicos que no se han encontrado aún en la región, pero que son motivos muy comunes a lo largo del Imperio.
- Pieza Nº 1620 en Ambrosetti (1907-1908: 327): Se trata de un puco con decoración interna dividida de forma cuadripartita por dos bandas reticuladas cruzadas (Figura 14a). Como se ve en la Figura 10 (centro), las bandas reticuladas aparecen en los platos inkas.

- Piezas $\mathrm{N}^{\circ} 793 \mathrm{ME}, \mathrm{N}^{\circ} 1680$ en Ambrosetti (19071908: 328) y $\mathrm{N}^{\circ} 2425$ MAC: Los dos primeros son pucos recuperados en las excavaciones de Ambrosetti en La Paya. Éstos presentan líneas de rombos, motivo típico y frecuente de la cerámica inka (Figura 14b, Pieza $\mathrm{N}^{\circ}$ 1680). Una línea de rombos también se encontró en la base de la olla campanuliforme $\mathrm{N}^{\circ} 2425$. Sin embargo, en el caso inka la decoración se realizaba a través de varias líneas de rombos pequeños colocadas paralela y horizontalmente (Figura 13, motivo 19). Además, este motivo, así como la manera en que los rombos están dispuestos en los dos pucos, son comunes en la cerámica santamariana del Período Tardío del área de Yocavil, a aproximadamente $160 \mathrm{~km}$ valle abajo (Weber 1981).

- Pieza $N^{\circ} 2111$ ME: También de las excavaciones de Ambrosetti en La Paya, se recuperó una ollita de borde invertido y labio convexo que presenta un aplique de cabeza de pájaro (Figura 14c), muy común en los platos inkas distribuidos a lo largo de todo el Imperio (Bray 2003; Hyslop 1993) (ver Figuras 9 y 11).

- Piezas $\mathrm{N}^{\circ} 926$ y $\mathrm{N}^{\circ} 1955 \mathrm{ME}$ : Se trata de una olla de borde invertido y labio convexo y una olla de cuello y bordes evertidos con decoración externa. En éstas fueron dibujados unos espirales que se encastran unos con otros. Esta forma de articulación del motivo de espiral se ve frecuentemente en la cerámica Inka Mixta de la región conocida como Inka Paya. En la alfarería calchaquí, por su parte, los espirales suelen ser independientes unos de otros. De todos modos, esta forma de articulación entre motivos se ve comúnmente en las grecas de las vasijas calchaquíes, las cuales son motivos muy similares a los espirales (Figura 13, motivo 4).

- Piezas $N^{\circ} 808$ en Ambrosetti (1907-1908: 394) y $\mathrm{N}^{\circ} 2444$ MAC: La decoración interna del puco $\mathrm{N}^{\circ} 808$ (Figura 14d) cuenta con un motivo que recuerda al número 38 de la Figura 13. Un dibujo parecido se presenta en el interior del puco $\mathrm{N}^{\circ} 2444$. 
Tres motivos generaron dudas por encontrarse comúnmente en la cerámica calchaquí e inka. Sin embargo, luego de su análisis se puede decir que no se pueden considerar producto de la influencia inka sobre la cerámica local. Uno de estos motivos son las líneas individuales de triángulos rellenos que aparecen en varias piezas calchaquíes (Figura 13, motivo 7). ${ }^{18}$ No obstante, en ningún caso se asemeja a la cerámica del Tawantinsuyu donde las líneas de triángulos fueron dispuestas de manera horizontal y combinando varias líneas de triángulos pequeños (Figura 8, izquierda). Otro motivo son los triángulos reticulados, los cuales no son típicos de la cerámica inka clásica pero aparecen en la cerámica inka encontrada en el valle Calchaquí Norte (Figura 13, motivos 7 y 30 ). Un número pequeño de vasijas calchaquíes exhiben estos triángulos. ${ }^{19}$ Una de ellas (pie$\mathrm{za} \mathrm{N}^{\circ} 4142 \mathrm{MAC}$ ) fue recuperada por nuestro proyecto de investigación de un entierro del Período Tardío del sitio Mariscal, lo que demuestra que el triángulo reticulado es un diseño local pre-inka. El tercer motivo son los espirales. Aunque éstos son comunes en la alfarería local, se detectaron algunos espirales grandes y en algunos casos de líneas finas que recordaban a los presentes en la cerámica Inka Paya del valle Calchaquí Norte. ${ }^{20}$ Sin embargo, hay diferencias con la cerámica Inka Paya. En ésta todos los motivos están realizados con trazado más fino y los espirales se dibujan achatados (Figura 13, motivo 33).

En solo nueve (3,6\%) de 247 vasijas locales se detectaron rasgos decorativos de posible influencia inkaica; aunque dicha influencia es más clara en el caso de las piezas $\mathrm{N}^{\circ}$ 1620 y $\mathrm{N}^{\circ} 2111$, y más dudosas en los otros siete ejemplos. Es interesante que no se haya encontrado ninguna vasija calchaquí decorada al estilo inka en su totalidad. Así, la cerámica calchaquí se mantuvo sin grandes cambios durante el período de dominación inka sobre la región. Aunque la recientemente formada elite de La Paya/Guitián comenzaba a emplear cultura material inka para representar su estatus y legitimar su poder, la gran mayoría de los norcalchaquíes continuaron produciendo y reproduciendo el

\footnotetext{
${ }_{18}$ Por ejemplo: piezas $\mathrm{N}^{\circ} 215,2845,3044,3138,3689$ y 4115 MAC y $\mathrm{N}^{\circ} 1280 \mathrm{ME}$.

19 Piezas $N^{\circ}$ 920, 1740, 1954, 2084 y $2059 \mathrm{ME}, \mathrm{N}^{\circ} 4142 \mathrm{MAC}$, $\mathrm{N}^{\circ} 987$ y 995 en Ambrosetti (1907-1908: 397-399), y Nº31 en Debenedetti (1908:25).

${ }^{20}$ Piezas N ${ }^{\circ} 630 \mathrm{ME}, \mathrm{N}^{\circ} 789$ y N ${ }^{\circ} 1972$ en Ambrosetti (19072008: 346 y 350), $\mathrm{N}^{\circ} 3203$ y $4151 \mathrm{MAC}, \mathrm{y} \mathrm{N}^{\circ} 630$ en Debenedetti (1908: 23).
}

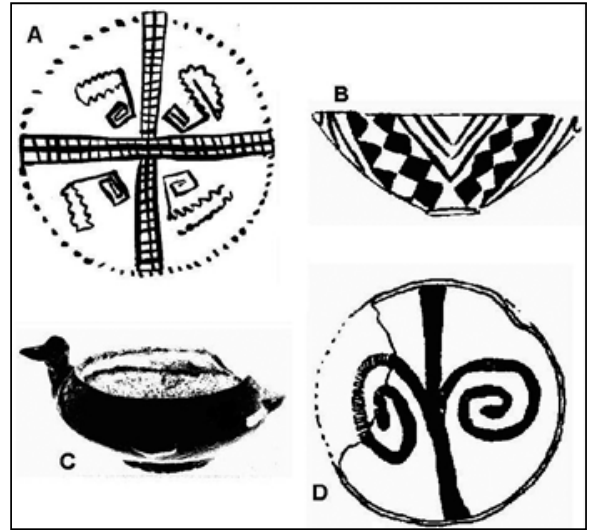

Figura 15. Vasijas calchaquíes con posibles influencias inkas.

estilo y los símbolos locales. Podría pensarse entonces que los alfareros locales decidieron mantener fuera de sus vasijas los símbolos de sus dominadores y de su dominación.

Este no parece haber sido el caso en regiones vecinas ni en el valle Calchaquí Norte en tiempos de la colonización española. Si bien aún no se ha realizado un estudio sistemático, se han encontrado en el cercano valle de Yocavil vasijas santamarianas con decoración inka. En la Figura 15a, por ejemplo, puede observarse una urna santamariana con una banda central vertical compuesta por rombos concéntricos. Tanto el motivo como la forma en que éste se dispuso en la pieza son típicos de los aríbalos inkas (Figura 15b). Por su parte, la conquista española traería grandes rupturas en la organización social de las poblaciones nor-calchaquíes (Gamarra 2008). Una de estas rupturas se produjo en la producción alfarera. Las vasijas cambiaron su morfología y comenzaron a emplear estructuras de diseño y motivos inkaicos (Figura 15, abajo). Ambas situaciones resultan un contrapunto interesante con lo que sucedía en el valle Calchaquí Norte en época de colonización Inka, y nos muestran cómo en este contexto primó la búsqueda ortodóxica por preservar lo local frente a la influencia foránea, algo que se modificaría con el tiempo.

\section{Discusión}

Hasta aquí hemos visto que no hay evidencia que indique que la cerámica decorada haya sido influida por el estilo inka en aspectos como la iconografía, las formas de organizar la decoración y las técnicas de dibujo. Si bien 
podrían haber incorporado elementos decorativos inkas a sus vasijas, las unidades domésticas nor-calchaquíes parecen haber ignorado intencionalmente los diseños e iconografía inkaica y relacionados con el Tawantinsuyu, y no los pintaron en sus significativas vasijas cerámicas. Algo similar pasó con la arquitectura. La gente local no parece haber estado interesada en emular, ni total ni parcialmente, las formas y técnicas arquitectónicas inkas. Mientras que un grupo pequeño de personas de La Paya/ Guitián aceptaron y negociaron la dominación inka (lo que les dio ciertas ventajas y un mayor estatus), la mayoría de los habitantes de la región pusieron en práctica estrategias ortodóxicas a través de actos de resistencia cultural contra el Tawantinsuyu. Ahora bien, ipor qué las comunidades colonizadas se aferraron a la tradición en estas dos esferas? Se podría afirmar que tanto la casa como la alfarería fueron dos importantes ámbitos de producción y reproducción de la vida social nor-calchaquí; de sus principios, valores, cosmología y memorias.

Los espacios domésticos fueron loci de central trascendencia dentro de la dinámica social nativa. Como fue dicho, varias e importantes esferas de la vida social vernácula estaban total o parcialmente centradas en los poblados en general y en los complejos residenciales en particular, tales como la vida doméstica, la reproducción biológica, la socialización, el establecimiento de los lazos familiares y comunales, el almacenaje, el consumo de alimentos, el entierro de los difuntos, la relación con los animales domésticos y la producción de la mayor parte de la cultura material (Acuto et al. 2008; D'Altroy et al. 2000; Díaz 1978-1984; Gifford 2003; Pollard 1983).

La sociedad nor-calchaquí puede ser considerada lo que en la literatura antropológica se ha denominado house society (Carsten y Hugh-Jones 1995). En este tipo de sociedades la vida social y material se organiza, desarrolla y reproduce dentro de las residencias. La casa, como unidad social y ambiente construido, tiene un rol dominante en la organización social y es un agente primario de socialización; “...las casas representan a los grupos sociales y al mundo alrededor de ellos" (Carsten y Hugh-Jones 1995: 1, traducción propia). Debido a que el mundo, las categorías sociales y la cosmología son experimentados, aprehendidos y corporizados dentro de las residencias, la casa tiene un papel central en la constitución de la subjetividad. En las house societies la morada es una unidad social que va más allá de sus habitantes, las prácticas de subsistencia y el parentesco. Más que esto, la casa, tal como también ha sido mostrado para el mundo andino (Arnold et al. 1992), es el locus donde se entrelazan la economía, la interacción social, el parentesco, los rituales, la cosmología, la memoria, los ancestros, las metáforas sobre el mundo, la materialidad y las personas.

La arquitectura y la ordenada organización espacial del ambiente construido inka fueron, sin dudas, unas de las marcas registradas más destacadas de la dominación del Tawantinsuyu sobre territorios provinciales (Gasparini y Margolis 1980; Hyslop 1990; 1993). Los rasgos particulares de la arquitectura y del diseño espacial inka han permitido a los arqueólogos identificar fácilmente los sitios y edificios inkas en distintas partes de los Andes. Estos rasgos materiales también debieron haber sido altamente reconocibles por los súbditos del Imperio en el pasado. La arquitectura inka, marcadamente distinta a la norcalchaquí, fue seguramente un rasgo notorio en el paisaje local. Así, su imitación y uso por nativos del valle Calchaquí Norte debió haber constituido un dramático acto de ruptura, tanto con la tradición como con la homogeneidad material de los poblados indígenas. Al mantenerse intacta la casa nor-calchaquí en términos de localización, formas arquitectónicas y organización del espacio, los colonizados enunciaban su apego a la tradición y memoria, como a la semejanza y articulación, aferrándose a su mundo de la vida cotidiana por sobre el cambio que propiciaba la colonización inkaica.

Las altamente decoradas vasijas calchaquíes, de producción doméstica no especializada, estuvieron amplia y homogéneamente distribuidas entre las comunidades y unidades domésticas del valle Calchaquí Norte, participando de un número importante de campos sociales: doméstico, funerario, así como en la construcción de una identidad regional frente a otras sociedades y como articuladoras e integradoras de las comunidades locales (Tarragó et al. 1997).

Las vasijas cerámicas comprendieron una gran proporción del mundo material de las sociedades nor-calchaquíes y fueron uno de los principales objetos materiales sobre los cuales las comunidades de esta región plasmaban sus símbolos. Las urnas y pucos calchaquíes, así como otras formas de vasijas decoradas, fueron lienzos 
altamente visibles, y ampliamente distribuidos, sobre los cuales símbolos y significados fueron expuestos, comunicados y compartidos. Estas piezas operaban como medio de comunicación material que servía para transmitir significados y quizá para narrar mitos e historias. La alfarería hacía circular estos símbolos y narrativas dentro de varias esferas y actividades, otorgando a estos significados una presencia cotidiana.

Además, y más allá de lo que los motivos pintados en las vasijas pudieran haber significado, la cerámica decorada fue un símbolo de la homogeneidad, semejanza y redundancia material que se experimentaba en los poblados nor-calchaquíes. En otro lugar, y a partir del análisis de 122 vasijas calchaquíes, hemos mostrado que los nor-calchaquíes prácticamente apelaron a una única estructura de diseño para organizar la decoración de sus vasijas, caracterizada por la dualidad y la simetría, con algunos pocos casos de simetría alterna (Acuto et al. 2012). Más del $95 \%$ de las piezas analizadas se decoraron a partir de un eje central con motivos a ambos lados de este eje que se reflejan entre sí (Figura 7). Asimismo, se comprobó que las caras de las urnas son casi siempre idénticas. Sumado a esto, hemos observado que el repertorio de motivos empleados para decorar las vasijas fue reducido y altamente redundante. De las 122 piezas analizadas se registraron un total de 546 motivos, los cuales fueron divididos en 12 tipos. Dentro de ellos, cuatro fueron los dibujos más populares, abarcando el 70\% de la muestra: grecas (Figura 13, motivo 4), líneas paralelas, espirales (Figura 13, motivo 5) y serpentiformes (Figura 13, motivos 11 a 14); alcanzándose el $90 \%$ si a éstos se suman los rostros (Figura 13, motivo 1) y los chevrones (Figura 13, motivo 15). En pocas palabras, la gran mayoría de la decoración de las vasijas se llevó a cabo a partir del uso de seis motivos. En este punto es interesante notar que hemos detectado una muy baja proporción $(0,73 \%)$ de motivos únicos y no repetidos. La popularidad de estos seis elementos decorativos se verifica cuando analizamos su ubicuidad, que fue de 75,4\% para los primeros cuatro, es decir están presentes en más del 70\% del total de las piezas estudiadas, y $100 \%$ si se consideran lo seis mencionados.

En pocas palabras, cuando las personas recorrían su pueblo, o incluso visitaban otras comunidades de la región, se topaban una y otra vez con los mismos motivos y una manera muy restringida de inscribirlos en las vasijas.
La gran redundancia que exhibían las representaciones visuales plasmadas en contenedores cerámicos, en conexión con la arquitectura y los objetos que definían la vida cotidiana en los poblados conglomerados, creaban un fuerte ethos de similitud e interconexión, participando en la creación de una vida social que desalentaba la diferencia y propiciaba la homogeneidad y permeabilidad (los motivos cruzaban fronteras dentro de una comunidad, entre comunidades, entre la vida y la muerte).

Mientras que la cerámica local conformaba una metáfora de la integración y la semejanza, la posesión de la inka encarnaba la fragmentación y la distinción. Una representaba la doxa y la otra la ruptura de ésta por la intervención colonial. En este contexto de colonialismo, la ausencia de decoración inka en la alfarería local indica que los nor-calchaquíes eligieron preservar no solo ciertos significados y narrativas simbólicas propias, sino también resguardar un símbolo de la homogeneidad comunal y la identidad regional.

\section{* Conclusión}

Como todo proceso de contacto cultural y colonialismo, la irrupción inka sobre el valle Calchaquí Norte produjo transformaciones en la vida social de las comunidades nativas de la región. La situación de dominación puso en evidencia al menos algunos aspectos del mundo de la vida nor-calchaquí. Así, lo que solía estar dado por sentado, aquello que se reproducía sin cuestionamientos, pasó a quedar expuesto y mostrar su carácter arbitrario ante la aparición de nuevas posibilidades. Bajo esta situación, ciertas personas aprovecharon las oportunidades que el contexto colonial ofrecía para transponer las limitaciones estructurales de la vida social indígena. Sin embargo, al mismo tiempo que algunos buscaban trascender el orden social nor-calchaquí, otros llevaban a cabo acciones ortodoxas orientadas a preservarlo.

Uno de los principales efectos que la dominación del Tawantinsuyu tuvo sobre la vida social del valle Calchaquí Norte fue la transformación de la idea local de agencia y de la agencia misma de algunas personas. Si bien previo a la conquista inka los jefes locales habrían tenido un poder temporal, actuando como líderes en situaciones de conflictos o articulaciones intercomunales, lo que no les 
reportaba beneficios materiales o sociales; a partir de la ocupación inka surgieron ciertos individuos que contaban con un poder institucionalizado, mayor autonomía y una nueva y superior potencialidad para la acción. Por supuesto, entre estos nuevos individuos estaban los representantes del Imperio mismos, quienes, a diferencia de cualquier jefe local, tenían la capacidad para controlar y tomar decisiones sobre la totalidad de la región. La praxis inka, por tanto, fue más allá de lo que cualquier nativo del valle alguna vez había alcanzado.

La colonización también amplió la agencia local. El contexto colonial en la región propició acciones tendientes a romper con el mundo de la vida nor-calchaquí, creando una heterodoxia. Como se vio en el caso de la comunidad de La Paya/Guitián, bajo la ocupación inka algunas personas comenzaron a destacarse notoriamente del resto, algo que no se había dado hasta entonces. Estas personas aprovecharon la nueva situación política en la región para mejorar su posición e incrementar su poder. A través de su asociación con los colonizadores y la cultura material inkaica, se transformaron en la elite institucionalizada de esta comunidad local. La recientemente formada elite de La Paya/Guitián no solo rompió con la articulación y homogeneidad vivida en los poblados locales a partir del monopolio sobre la arquitectura y el consumo de bienes inkas, sino que también adquirió el conocimiento (y fue beneficiada con el poder) para conducir rituales inkas dentro de contextos locales.

El surgimiento de estos agentes nativos debió haber transformado la concepción y percepción local de la agencia. En este nuevo contexto de colonización aparecieron personas que superaron los constreñimientos estructurales de la época pre-inka y que adquirieron más poder y nuevos conocimientos que ampliaron su capacidad de acción. Sin embargo, la posición de estos nuevos agentes pudo haber tenido un lado negativo al producir una comunidad fragmentada y alienar a esta elite del resto del pueblo y de las redes sociales y económicas de solidaridad existentes antes de los inkas. El rechazo social pudo haber sido una de las consecuencias no intencionadas de estas nuevas formas de praxis promovidas por los inkas.

Así como hubo personas dispuestas a transformar su posición beneficiada por la alianza con los colonizadores foráneos, la mayoría de los habitantes del valle Cal- chaquí Norte parecen haber llevado adelante acciones en pos de preservar al menos dos aspectos significativos de la vida social y las prácticas culturales nativas: los espacios domésticos y la cerámica decorada y su simbología. Estos dos campos sociales elegidos para resistir la dominación inka fueron importantes esferas de la vida social nor-calchaquí. La cerámica calchaquí fue el artefacto más visible y ubicuo producido por las comunidades de la región, participando de contextos domésticos, rituales y funerarios. Estos objetos también fueron significativos por servir de lienzos o soportes para la expresión de una variedad de símbolos. El estilo cerámico santamariano o calchaquí fue uno de los sellos distintivos de la cultura local, símbolo de la homogeneidad material y semejanza experimentada en los poblados indígenas. Por su parte, los complejos residenciales fueron uno de los más importantes loci de actividades y de la reproducción social de las comunidades nor-calchaquíes. Mientras que un pequeño grupo de personas, especialmente de La Paya/Guitián, incorporaron y emplearon estratégicamente la cultura material inka, la mayoría de los pobladores de esta región desafiaron la influencia inka y resistieron la "contaminación" que los artefactos inkas pudieron haber generado en dos de los más significativos campos sociales vernáculos.

Agradecimientos Quiero agradecer especialmente a los miembros de mi equipo de investigación, quienes han contribuido significativamente con el desarrollo del proyecto y han hecho de cada trabajo de campo una experiencia alegre y productiva: Claudia Amuedo, Marisa Kergaravat, Alejandro Ferrari, Cristián Jacob, Lucila Gamarra, Ana Laura Goldín, Ezequiel Gilardenghi, Marina Smith, Martín Vilariño y Maximiliano Tello. También a la directora del Museo de Cachi, Lic. Mónica De Lorenzi, cuya amabilidad y buena disposición han facilitado grandemente nuestro trabajo. Así también al personal del Museo de Cachi por su constante ayuda: Lili, Ica, Lidia, Demetrio Salvatierra, Marta, Manuela, Diego y Carlos. Por último quiero agradecer al co-director de este proyecto, Andrés Troncoso, por su buena onda y estimulantes ideas. Este proyecto ha sido desarrollado a partir de subsidios Wenner-Gren Foundation for Anthropological Research, International Collaborative Research Grant 2007; Heinz Grant for Latin American Archaeology 2007 y Programación Científica UBACyT 2006/2009, Universidad de Buenos Aires. Resolución (CS) N 508 o6, Expediente $\mathrm{N}^{\circ} 35931 / 05$. 


\section{* Referencias citadas}

ACUTO, F. A. 2004. Landscapes of ideology and inequality: Experiencing Inka domination. Ph. D. Dissertation, State University of New York, Binghamton.

2007. Fragmentación vs. integración comunal: Repensando el Período Tardío del Noroeste Argentino. Estudios Atacameños 34: 71-95.

2008. Materialidad, espacialidad y vida social. Reinterpretando el Período Prehispánico Tardío de los Andes del Sur. En Sed Non Satiata II. Acercamientos sociales en la arqueología latinoamericana, F. Acuto y A. Zarankin (Eds.), pp. 159-193. Encuentro Grupo Editor, Córdoba.

2010. Living under the imperial thumb in the Northern Calchaquí Valley (Argentina). En Distant provinces in the Inka Empire: Toward a deeper understanding of Inka imperialism, M. Malpass y S. Alconini (Eds.), pp. 108-150. University of Iowa Press, Iowa City.

ACUTO, F. A., C. AMUEDO, M. KERGARAVAT, A. FERRARI, L. GAMARRA y A. GOLDÍN, 2008. Experiencias subjetivas en las aldeas prehispánicas del valle Calchaquí Norte: Arqueología de la vida cotidiana, prácticas y relaciones sociales durante el Período Tardío. En Arqueología del extremo sur del continente americano. Resultados de nuevos proyectos, L. A. Borrero y N. V. Franco (Eds.), pp. 11-54. CONICET - IMHICIHU, Buenos Aires.

ACUTO, F. A., E. GILARDENGHI y M. SMITH, 2012. Rehenebrando el pasado. Hacia una epistemología de la materialidad. Boletín del Museo Chileno de Arte Precolombino. En prensa.

ACUTO, F. A., M. KERGARAVAT y C. AMUEDO. 2011. Experiencia de la muerte y la representación de las personas en las prácticas funerarias del valle Calchaquí Norte. Comechingonia 14: 23-54.

ALCONINI, S. 2010. Yampara households and communal evolution in the southeastern Inka peripheries. En Distant provinces in the Inka empire: Toward a deeper understanding of Inka imperialism, M. Malpass y S. Alconini (Eds.), pp. 75-107. University of Iowa Press, Iowa City.

AMBROSETTI, J. B. 1902. El sepulcro de La Paya últimamente descubierto en los Valles Calchaquíes, provincia de Salta. Anales del Museo Nacional 8: 119-148.

1907-1908. Exploraciones arqueológicas en la ciudad prehistórica de La Paya (valle Calchaquí, pcia. de Salta). Universidad de Buenos Aires, Buenos Aires.
ARNOLD, D., D. JIMÉNEZ y J. YAPITA, 1992. Hacia un orden andino de las cosas: tres pistas de los Andes meridionales. Hisbol, La Paz.

BOMAN, E. 1908. Antiquités de la región andine de la République Argentine et du Désert D'atacama. 2 vol. Paris.

BOURDIEU, P. 1977. Outline of a theory of practice. Cambridge University Press, Cambridge.

1999. Meditaciones pascalianas. Editorial Anagrama, Barcelona.

2007. El sentido práctico. Siglo XXI Editores, Buenos Aires.

BRAY, T. 2003. Inka pottery as culinary equipment: Food, feasting, and gender in imperial state design. LatinAmerican Antiquity $14(1): 3-28$.

CARSTEN, J. y S. HUGH-JONES, 1995. Introduction. En About the house, J. Carsten y S. Hugh-Jones, (Eds.), pp. 1-46. Cambridge University Press, Cambridge.

COMAROFF, J. L. y J. COMAROFF, 1991. Of revelation and revolution: Christianity, colonialism, and consciousness in South Africa, vol 1. University of Chicago Press, Chicago.

1997. Of revelation and revolution: The dialectics of modernity on a South African frontier, vol. 2. University of Chicago Press, Chicago.

COOPER, F. y A. L. STOLER (Eds.), 1997. Tensions of empire. Colonial cultures in a bourgeois world. University of California Press, Berkeley.

D’ALTROY, T., A. M. LORANDI y V. I. WILLIAMS, 1994. Producción y uso de la cerámica en la economía política Inca. Arqueología 4: 73-172.

D'AlTROY, T., A. LORANDI, V. I. WILLIAMS, M. CALDERARI, C. HASTORF, E. DEMARRAIS y M. HAGSTRUM, 2000. Inka rule in the Northern Calchaquí Valley, Argentina. Journal of Field Archaeology 27: 1-26.

DAVIN, A. 1997. Imperialism and motherhood. En Tensions of empire. Colonial cultures in a bourgeois world, F. Cooper y A. L. Stoler (Eds.), pp. 87-151. University of California Press, Berkeley.

DE LORENZI, M. y P. P. DÍAZ, 1976. La ocupación incaica en el sector septentrional del valle Calchaquí. Revista del Museo de Historia Natural de San Rafael (Mendoza) 2(1/4): 75-88.

DEMARRAIS, E. 1997. Materialization, ideology and power: The development of centralized authority among pre-Hispanic polities of the Valley 
Calchaquí, Argentina. Tesis de doctorado, University of California, Los Angeles.

2001. La arqueología del norte del Valle Calchaquí. En Historia prehispánica argentina, Tomo I. E. Berberián y A. Nielsen (Eds.), pp. 289-346. Editorial Brujas, Córdoba.

DÍAZ, P. P. 1978-1984. Diario de la excavación realizada en el sitio Tero SSalCac 14. Informe depositado en el Museo Arqueológico de Cachi, Cachi. MS.

198. Diario de excavación realizada en el sitio La Paya SSalCac 1. Informe depositado en el Museo Arqueológico de Cachi, Cachi. MS.

1992. Sitios arqueológicos del valle Calchaquí IV. Estudios de Arqueología 5: 63-77.

DIELTER, M. 1998. Consumption, agency and cultural entanglement: Theoretical implications of a Mediterranean colonial encounter. En Studies in cultural contact: Interaction, culture change and archaeology, J. Cusick (Ed.), pp. 288-315. Occasional Paper 25, Southern Illinois University, Carbondale.

DILLEHAY, T. D. 2003. El colonialismo Inka, el consumo de chicha y los festines desde una perspectiva de banquetes políticos. Boletín de Arqueología PUCP 7:355-363.

DIRKS, N. (Ed.), 1992. Colonialism and culture. University of Michigan Press, Ann Arbor.

DOBRES, M-A. y J. ROBB, 2000. Agency in archaeology: Paradigm or platitude? En Agency in archaeology, M.-A. Dobres y J. Robb (Eds.), pp. 3-17. Routledge, Londres \& Nueva York.

DORNAN, J. L. 2002. Agency and archaeology: Past, present and future directions. Journal of Archaeological Method and Theory 9: 303-329.

EARLE, T. K. 1994. Wealth finance in the Inka Empire: Evidence from the Calchaquí valley, Argentina. American Antiquity 59(3): 443-460.

GAMARRA, L. 2008. Representando al mundo desde un mundo Nuevo. Trayectorias y rupturas en las prácticas funerarias y el estilo cerámico en el valle Calchaquí Norte (Salta) durante el Periodo Hispano Indígena (siglos XVI-XVII). Tesis de licenciatura, Facultad de Filosofía y Letras, Universidad de Buenos Aires.

GASPARINI, G. y L. MARGOLIES, 1980. Inca architecture. Indiana University Press, Bloomington.

GIDDENS, A. 1979. Central problems in social theory. MacMillan, Londres.
1995. La constitución de la sociedad. Bases para la teoría de la estructuración. Amorrortu Editores, Buenos Aires.

GIFFORD, C. 2003. Local matters: Encountering the imperial Inkas in the South Andes. Tesis de doctorado, Columbia University, Nueva York.

GONZÁLEZ, A. R. 1982. Las "provincias" Inca del antiguo Tucumán. Revista del Museo Nacional XLVI: 317-380.

GONZÁLEZ, A. R. y P. P. DÍAZ, 1992. Notas arqueológicas sobre la "Casa Morada", La Paya, pcia. de Salta. Estudios de Arqueología 5:9-61.

GROSBOLL, S. 1993. "...And He Said in the Time of the Ynga, They Paid Tribute and Served the Ynga". En Provincial Inca: Archaeological and ethnohistorical assessment of the impact of the Inca State, M. Malpass (Ed.), pp. 44-76. University of Iowa Press, Iowa.

HABERMAS, J. 1987. Teoría de la acción comunicativa II: Crítica de la razón fundamentalista. Taurus, Madrid.

HALL, C. 2000 . Introduction: Thinking the postcolonial, thinking the empire. En Cultures of Empire: A Reader, C. Hall (Ed.), pp. 1-33. Routledge, Nueva York.

HAYASHIDA, F. 2003. Leyendo el registro arqueológico del dominio inka: Reflexiones desde la costa norte del Perú. Boletín de Arqueología PUCP 7: 305-319.

HYSLOP, J. 1990. Inka settlement plannig. University of Texas Press, Austin.

1993. Factors influencing the transmission and distribution of Inka cultural materials throughout Tawantinsuyu. En Latin American Horizons, D. Rice (Ed.), pp. 337-56. Dumbarton Oaks Research Library and Collection, Washington, D.C.

JENNINGS, J. 2003. Inca imperialism, ritual change, and cosmological continuity in the Cotahuasi Valley of Peru. Journal of Anthropological Research 59(4): 433-462.

KING, A. 1979. Colonial urban development: Culture, social power and environment. Routledge \& Paul Keagan, Londres.

KRAPOVICKAS, P. 1983. Las poblaciones indígenas históricas del sector oriental de la Puna (un intento de correlación entre la información etnohistórica y la etnográfica). Relaciones de la Sociedad Argentina de Antropología 15: 7-24.

LEIBOWICZ, I. 2007. Espacios de poder en La Huerta, quebrada de Humahuaca. Estudios Atacameños 34: 51-69. 
LORANDI, A. M. y R. BOIXADÓS, 1987-88. Etnohistoria de los Valles Calchaquíes en los siglos XVI y XVII. Runa XVII-XVIII: 263-419.

MACKEY, C. 2003. La transformación socioeconómica de Farfán bajo el gobierno Inka. Boletín de Arqueología PUCP 7: 321-353.

MENZEL, D. 1959. The Inca occupation of the South Coast of Peru. Southwestern Journal of Anthropology 15 (2): 125-42.

MITCHELL, T. 1988. Colonizing Egypt. University of California Press, Berkeley.

MUÑOZ, I. y J. CHACAMA, 1999. Los valles serranos de Arica y Tacna en la órbita de los Incas. Actas del XII Congreso Nacional de Arqueología Argentina, Tomo I: 262-79.

PAUKETAT, T. 2001. Practice and history in archaeology: An emerging paradigm. Anthropological Theory 1(1): 73-98.

POLLARD, G. 1983. Nuevos aportes a la prehistoria del valle Calchaquí, noroeste argentino. Estudios de Arqueología 3-4: 69-92.

PRAKASH, G. 2000. Subaltern studies as colonial criticism. En Cultures of Empire: A Reader, C. Hall (Ed.), pp. 120-136. Routledge, Nueva York.

RABINOW, P. 1989. French modern: Norms and forms of the social environment. MIT Press, Cambridge, MA.

RAFFINO, R. A. 1983. Arqueología y etnohistoria de la región Calchaquí. En Presencia hispánica en la arqueología argentina, E. Morresi y R. Gutierrez (Eds.), pp. 817-861. Instituto de Historia, Facultad de Humanidades, Universidad Nacional del Noreste, Chaco.

RIVERA, C. 2010. Forms of imperial control and the negotiation of local autonomy in the Cinti Valley of Bolivia. En Distant provinces in the Inka Empire: Toward a deeper understanding of Inka imperialism, M. Malpass y S. Alconini (Eds.), pp. 151-172. University of Iowa Press, Iowa.

ROSSEN, J., M. T. PLANELLA y R. STEHBERG, 2010. Archeobotany of Cerro del Inga, Chile, at the southern Inka frontier. En Distant provinces in the Inka Empire: Toward a deeper understanding of Inka imperialism, M. Malpass y S. Alconini (Eds.), pp. 14-43. University of Iowa Press, Iowa.
SAID, E. 1993. Culture and imperialism. Knopf, Nueva York.

SCHREIBER, K. 1993. The Inca occupation of the province of Andamarca Lucanas, Peru. En Provincial Inca: Archaeological and ethnohistorical assessment of the impact of the Inca State, M. Malpass (Ed.), pp. 77-116. University of Iowa Press, Iowa.

SCHUTZ, A. y T. LUCKMANN, 1977. Las estructuras del mundo de la vida. Amorrortu Editores, Buenos Aires.

STOLER, A. L. 1995. Race and the education of desire: Foucault's History of Sexuality and the colonial order of things. Duke University Press, Durham.

TARRAGO, M. 2000. Chakras y pukara. Desarrollos sociales tardíos. En Los pueblos originarios y la conquista, Nueva historia argentina, Tomo I, M. Tarragó (Ed.), pp. 257-300. Editorial Sudamericana, Buenos Aires.

TARRAGÓ, M., L. GONZÁLEZ y J. NASTRI, 1997. Las interrelaciones prehispánicas a través del estilo: El caso de la iconografía santamariana. Estudios Atacameños 14: 223-42.

THOMAS, N. 1991. Entangled objects: Exchange, material culture, and colonialism in the Pacific. Harvard University Press, Cambridge, MA.

1994. Colonialism's culture. Anthropology, travel and government. Princeton University Press, Princeton, NJ.

1999. The Case of the misplaced ponchos. Speculations concerning the history of cloth in Polynesia. Journal of Material Culture $4(1): 5-20$.

TRONCOSO, A. 2004. El arte de la dominación: Arte rupestre y paisaje durante el período incaico en la cuenca superior del río Aconcagua. Chungará 36(2): 553-561.

VILLACORTA, L. F. 2003. Palacios y ushnus: Curacas del Rimac y gobierno inca en la costa central. Boletín de Arqueología PUCP 7: 151-187.

WEBER, R. 1981. An analisis of Santa Maria urn painting and its cultural implications. Fieldiana Anthropology 2: 1-32.

WILLIAMS, V. I. 2004. Poder estatal y cultura material en el Kollasuyu. Boletín de Arqueología PUCP 8: 209-246. 